\title{
REVIEW
}

Open Access

\section{Validity and reliability of subjective methods to assess sedentary behaviour in adults: a systematic review and meta- analysis}

Esmée A. Bakker ${ }^{1}{ }^{3}$, Yvonne A. W. Hartman ${ }^{1}$, Maria T. E. Hopman ${ }^{1}$, Nicola D. Hopkins², Lee E. F. Graves², David W. Dunstan ${ }^{3,4}$, Genevieve N. Healy ${ }^{5}$, Thijs M. H. Eijsvogels ${ }^{1}$ and Dick H. J. Thijssen ${ }^{1,2^{*}}$

\begin{abstract}
Background: Subjective measures of sedentary behaviour (SB) (i.e. questionnaires and diaries/logs) are widely implemented, and can be useful for capturing type and context of SBs. However, little is known about comparative validity and reliability. The aim of this systematic review and meta-analysis was to: 1 ) identify subjective methods to assess overall, domain- and behaviour-specific SB, and 2) examine the validity and reliability of these methods.

Methods: The databases MEDLINE, EMBASE and SPORTDiscus were searched up to March 2020. Inclusion criteria were: 1) assessment of SB, 2) evaluation of subjective measurement tools, 3) being performed in healthy adults, 4) manuscript written in English, and 5) paper was peer-reviewed. Data of validity and/or reliability measurements was extracted from included studies and a meta-analysis using random effects was performed to assess the pooled correlation coefficients of the validity.

Results: The systematic search resulted in 2423 hits. After excluding duplicates and screening on title and abstract, 82 studies were included with 75 self-reported measurement tools. There was wide variability in the measurement properties and quality of the studies. The criterion validity varied between poor-to-excellent (correlation coefficient $[R]$ range $-0.01-0.90)$ with logs/diaries $(R=0.63[95 \% \mathrm{Cl} 0.48-0.78])$ showing higher criterion validity compared to questionnaires $(R=0.35$ [95\% Cl 0.32-0.39]). Furthermore, correlation coefficients of single- and multiple-item questionnaires were comparable (1-item $R=0.34$; 2-to-9-items $R=0.35$; $\geq 10$-items $R=0.37$ ). The reliability of SB measures was moderate-to-good, with the quality of these studies being mostly fair-to-good.
\end{abstract}

Conclusion: Logs and diaries are recommended to validly and reliably assess self-reported SB. However, due to time and resources constraints, 1-item questionnaires may be preferred to subjectively assess SB in large-scale observations when showing similar validity and reliability compared to longer questionnaires.

Registration number: CRD42018105994.

Keywords: Sedentary behaviour, Sitting, Measurement, Self-report, Reliability, Validity

\footnotetext{
* Correspondence: Dick.Thijssen@radboudumc.nl

'Radboud Institute for Health Sciences, Department of Physiology, Radboud

University Medical Center, P.O. Box 9101, 6500, HB, Nijmegen, The

Netherlands

${ }^{2}$ Research Institute for Sport and Exercise Sciences, Liverpool John Moores

University, Liverpool, UK

Full list of author information is available at the end of the article
}

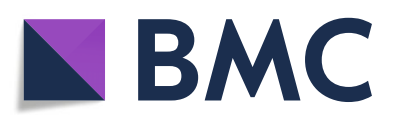

( ) The Author(s). 2020 Open Access This article is licensed under a Creative Commons Attribution 4.0 International License, which permits use, sharing, adaptation, distribution and reproduction in any medium or format, as long as you give appropriate credit to the original author(s) and the source, provide a link to the Creative Commons licence, and indicate if changes were made. The images or other third party material in this article are included in the article's Creative Commons licence, unless indicated otherwise in a credit line to the material. If material is not included in the article's Creative Commons licence and your intended use is not permitted by statutory regulation or exceeds the permitted use, you will need to obtain permission directly from the copyright holder. To view a copy of this licence, visit http://creativecommons.org/licenses/by/4.0/. The Creative Commons Public Domain Dedication waiver (http://creativecommons.org/publicdomain/zero/1.0/) applies to the data made available in this article, unless otherwise stated in a credit line to the data. 


\section{Introduction}

Regular physical activity reduces the risk of premature death, cardio- and cerebrovascular disease, metabolic disorders and some forms of cancer [1, 2]. Based on the overwhelming evidence, the World Health Organization recommend adults to perform $\geq 150$-min moderate-intensity aerobic physical activity, or $\geq 75$ min vigorous-intensity aerobic physical activity per week [3]. More recently, the importance of sedentary behaviour (SB) for health has emerged. High levels of $\mathrm{SB}$ are associated with an increased risk of premature death, cardiovascular disease, metabolic disorders and cancer [4-6], with especially strong associations in those who are physically inactive. These observations highlight the importance of accurately measuring physical activity and SB in order to understand their respective roles in health outcomes.

Various devices [7] and questionnaires [8] are available to assess physical activity. Since SB is a distinct behavioural entity and not simply reflective of the lack of sufficient physical activity, these measures may not directly assess SB [9]. Furthermore, in contrast with structured exercise, SB occurs habitually throughout the day, making valid assessment of $\mathrm{SB}$ challenging. $\mathrm{SB}$ is defined as any activity during awake time with an energy expenditure $\leq 1.5$ METs (i.e. sitting or activities in reclining posture) $[9,10]$. Patterns and total volume of SB can be assessed using objective measures such as thigh-worn accelerometers combining acceleration and posture, which is currently regarded as the gold standard to quantify freeliving SB and to distinguish between sitting or lying, standing and physical activity [11]. Nonetheless, used in isolation, these objective measures do not distinguish between different domains (e.g. occupation, transportation and leisure time) and settings (e.g. TV viewing, car driving and sitting while reading) of SB. This is important since some settings of sitting, e.g. TV viewing and screen time, are more strongly associated with poor health outcomes compared to total sedentary time [12-14] and may serve as useful intervention targets. These observations emphasise the need for valid subjective measures to assess SB within the various domains and settings in which it occurs. Ideally, these measures should be taken in combination with objective assessments [15]. However, given this is not always possible or feasible, it is also important to understand the measurement metrics of self-report methods when they are used in isolation.

Several self-reported tools (i.e. questionnaires, logs and diaries) have been developed recently to measure SB. These tools vary from single-item questions to extensive questionnaires about $\mathrm{SB}$ considering various domains. Currently, some reviews compared the validity and reliability of these tools [15, 16]. However, previous reviews did not take the risk of bias across studies into account and did not combine the results into a meta-analysis. Knowledge about the validity, reliability and the quality of the studies performed is essential to plan, perform and correctly interpret results in this field of research, because measurement error may seriously impact study results. The aim of this systematic review and metaanalysis was to identify subjective methods to assess SB and, subsequently, to examine their validity and reliability to assess SB in adults. Where the sedentary time measured by subjective methods was compared to objective and other subjective methods. This overview will contribute to improved selection of appropriate subjective measures of SB (in relation to their research question), and to identify gaps of knowledge within this area of research.

\section{Methods}

\section{Date source and literature search}

A literature search was performed in databases of MEDLINE, EMBASE and SPORTDiscus. The search strategy combined three main search terms: sedentary behaviour, self-reported measures, and validity/reproducibility. The complete search strategy is shown in the Additional Table 1. The last search was performed on March 11th, 2020. All citations were imported into the bibliographic database of EndNote, version X7 (Thomas Reuters, New York City, NY). This review was registered in PROSPERO (number CRD42018105994) and the 'Preferred Reporting Items for Systematic Reviews and MetaAnalyses' (PRISMA) [98] guidelines were used to perform the systematic review and meta-analyses.

\section{Selection of papers}

After importing all citations in Endnote, duplicates were removed, and title, abstract and full text were independently screened by two reviewers $(\mathrm{EB}, \mathrm{YH})$. In case of disagreement, a third reviewer (TE) was consulted. Inclusion criteria were: 1) assessment of $\mathrm{SB}, 2$ ) evaluation of subjective measurement tools, 3) being performed in healthy adults, 4) manuscript written in English, and 5) paper was peer-reviewed. Papers were excluded if the study did not aim to determine any construct of SB, when studies did not investigate the validation or reliability of the tool and/or the aim was to cross-cultural validate the subjective tool in different languages. A flowchart of the search strategy and the inclusion of manuscripts is presented in Fig. 1.

\section{Data extraction, synthesis and analysis}

Study characters were extracted using an extraction form including: 1) study population, 2) number of 
Table 1 Description of measurement tools to determine sedentary behaviour

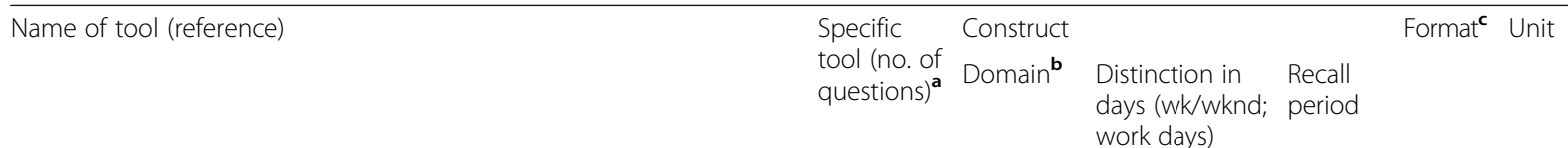

1-item questionnaires

EEPAQ; Elderly EXERNET Physical Activity Questionnaire [17]

GPAQ: Global Physical Activity Questionnaire [18-24]

IPAQ (short); International Physical Activity Questionnaire [25-27]

Q (1) To

Q (1) To

Q [1) To

Modified MOSPA-Q; MONICA Optional Study on Physical Activity

Q (1)

W

Questionnaire [28]

PPAQ; Paffenbarger Physical Activity Questionnaire [29]

SED-GIH [30]

Q (1) To no

Q (1) To no

SQ; Single Question [31-33]

TASST; TAxonomy of Self-report SB Tools [31, 34]

1) Single item total times; 2) Single item proportion; 3) TV time

T-SQ; Total sitting questionnaire [35]

TV-Q; TV viewing [35]

YPAS; Yale Physical Activity Survey for Older Adults [36]

Clemes et al. 2012 [33]

Gao et al. 2017 (57)

1) Single item proportion (3 months) 2) Single item proportion (1 day)

Gupta et al. 2017 [37]

Q (1) To

Q (1: 1, 2: To

$1,3: 1)$

Q (1) To

Q (1) To

I (1) To

Q (1) To

$Q(1: 1,2: \quad W$

1)

\section{2-9-item questionnaires}

AQuAA; Activity Questionnaire for Adults and Adolescents [38]

Cancer Prevention Study-3 Sedentary Time Survey [39]

CHAMPS; Community Health Activities Model Program for Seniors $[36,40]$

FPACQ; Flemish Physical Activity Computerized Questionnaire [41, 42]

Q (1)

(1) To

Q (4) L no

Q (4) To $+\mathrm{L}$ yes

Q (9) L L + other no

Q (3) $\quad$ To $+W+$ no

IPAQ (long); International Physical Activity Questionnaire [26, 43-47]

OPAQ; Occupational Physical Activity Questionnaire [48]

Q (2)

$\operatorname{Tr}$

OSPAQ; Occupational Sitting and Physical Activity Questionnaire [28, 49-51]

PAS2; Physical Activity Scale [52]

PASBAQ; Physical Activity and Sedentary Behavior Assessment Questionnaire [53]

PASB-Q; Physical Activity and Sedentary Behavior Questionnaire [54]

PAST-U; Past-day Adults' Sedentary Time University [55]

PAT Survey; Physical Activity and Transit Survey [56]

RPAQ; Recent Physical Activity Questionnaire $[57,58]$

Regicor Short Physical Activity Questionnaire [59]

SCCS PAQ; Southern Community Cohort Study Physical Activity Questionnaire [60]

SITBRQ: Workplace Sitting Breaks Questionnaire [61]

Stand Up For Your Health Questionnaire [36, 62]

STAQ; Sedentary, Transportation and Activity Questionnaire [63]

TASST; TAxonomy of Self-report SB Tools [31]

4) Patterns; 5) Sum of domains

Q $(2)$ no

Q (3) W no

Q (2) $\quad L+W \quad$ no

Q (3) $\quad L+W \quad$ no

Q (3) $\quad L+W \quad$ no

Q (9) $L+T r+W$ no

Q (2) To no

Q (4) $L+\operatorname{Tr} \quad$ no

Q (4) L yes

Q (6) $L+T r+W$ no

Q (2) W yes

I (7) $L+T r+W \quad$ no

Q (7) $\quad L+T r+W$ yes

Q (4: 2, 5: $\quad H+L+$ no

13) $\mathrm{Tr}+\mathrm{W}$

$Q(2)-(-2-5$

$\begin{array}{lcl}1 \text { wk } & \mathrm{T} & \text { Hrs (cat) } \\ - & \mathrm{T} & \mathrm{Hrs}+\mathrm{min} \\ 1 \text { wk } & \mathrm{T} & \mathrm{Hrs}+\mathrm{min} \\ - & \mathrm{T} & \mathrm{Hrs}+\mathrm{min}\end{array}$

Hrs Hrs (cat) $\mathrm{Hrs}+\min$ $\mathrm{Hrs}+\min$ $\%$

Hrs $+\min$ $\mathrm{Hrs}+\min$ Hrs Hrs + min $\%$ $3 \mathrm{~d} \quad \mathrm{~T} \quad \mathrm{Hrs}+\mathrm{min}$ $1 w k \quad \mathrm{~T} \quad \mathrm{Hrs}+\min$ $1 \mathrm{yr} \quad \mathrm{T} \quad$ Hrs (cat) 4 wk $T$ Hrs (cat)

- $\quad$ T Hrs

1 wk T Hrs + min

- $T$ Hrs

1 wk T \% of sitting

- $\quad \mathrm{T} \quad \mathrm{Hrs}+\min$

4 wk $T \quad H r s+$ min

- $\quad \mathrm{T} / \mathrm{Br} \quad \mathrm{Hrs}$ (cat) number

$1 d \quad \mathrm{~T} \quad \mathrm{Hrs}+\mathrm{min}$

$1 w k \quad \mathrm{~T} \quad \mathrm{Hrs}+\mathrm{min}$

4 wk $T$ Hrs (cat)

$T$ Hrs

- $\quad \mathrm{T} \quad \mathrm{Hrs}+\min$

\begin{tabular}{|c|c|c|}
\hline & $\mathrm{Br}$ & $\begin{array}{l}\text { Freq + } \\
\text { duration }\end{array}$ \\
\hline 1 wk & $\mathrm{T}$ & $\mathrm{Hrs}+\min$ \\
\hline wk & $\mathrm{T}$ & $\mathrm{Hrs}+\min (\mathrm{cat})$ \\
\hline & $\mathrm{T} / \mathrm{Bou}$ & $\begin{array}{l}\mathrm{Hrs}+\min \\
\text { no. of bouts }\end{array}$ \\
\hline
\end{tabular}


Table 1 Description of measurement tools to determine sedentary behaviour (Continued)

\begin{tabular}{lll}
\hline Name of tool (reference) & $\begin{array}{l}\text { Specific Construct } \\
\text { tool (no. of Domain }\end{array}$ & $\begin{array}{l}\text { Distinction in Recall } \\
\text { days (wk/wknd; period } \\
\text { questions) }\end{array}$ \\
& & work days)
\end{tabular}

Survey of older adults' sedentary time [64]
Web-based physical activity questionnaire Active-Q [65]
WSWQ; Percentage-Method Improves Properties of Workers' Sitting-
and Walking-Time Questionnaire [66]

Clark et al. 2011 [67]

Jefferis et al. 2016 [68]

Lagersted-Olsen et al. 2014 [69]

Mielke et al. 2020 [70]

Sudholx et al. 2012 [71]

Cartmel et al. 1992 [72]

Questionnaire A / B

\section{0-item questionnaires}

ASBQ: Adult Sedentary Behaviour Questionnaire [21]

D-SQ; Domain-Specific Questionnaire [35]

MPAQ; Madras Physical Activity Questionnaire [73]

MSTQ; Multicontext Sitting Time Questionnaire [74]

PAFQ: Physical Activity Frequency Questionnaire [75]

PAST-WEEK-U [76]

NIGHTLY-WEEK-U [76]

SBQ; Sedentary Behaviour Questionnaire [24, 43, 77]

SIT-Q; Sedentary Behavior Questionnaire [78]

SIT-Q-7d; last 7-d sedentary behavior questionnaire [79, 80]

STAR-Q [81]

TASST; TAxonomy of Self-report SB Tools [31] [34] 6) Sum of behaviours

WSQ; Workforce Sitting Questionnaire [50, 82, 83]

Clark et al. 2015 [84]

Clemes et al. 2012 [33]

Ishii et al. 2018 [85]

Marshall et al. 2012 [86]

Van Cauwenberg et al. 2017 [87]

Visser et al. 2010 [88]

Logs and diaries

7-day SLIPA Log; (7-day Sedentary and Light Intensity Physical Activity Log) [89]

BAR; Bouchard Activity Record [90]

BeWell24 Self-Monitoring App [91]

cpar24; Computer-Based 24-Hour Physical Activity Recall Instrument [92]

\begin{tabular}{|c|c|c|c|c|c|}
\hline & & & & & \\
\hline Q (8) & $L+T r+W$ & No & 1 wk & $\mathrm{T}$ & $\mathrm{Hrs}+\min$ \\
\hline Q (8) & $L+T r+W$ & no & $1 \mathrm{mo}$ & $\mathrm{T}$ & $\mathrm{Hrs}+\min (\mathrm{cat})$ \\
\hline $\mathrm{Q}(3 / 7)$ & $L+W$ & yes & $1 \mathrm{mo}$ & $\mathrm{T}$ & $\begin{array}{l}\mathrm{Hrs}+\min \\
\%\end{array}$ \\
\hline Q (2) & W & yes & 1 wk & $\mathrm{T} / \mathrm{Br}$ & $\begin{array}{l}\text { Hrs + min / } \\
\text { freq }\end{array}$ \\
\hline (4) & $L+\operatorname{Tr}$ & no & - & $\mathrm{T}$ & $\mathrm{Hrs}$ \\
\hline Q (4) & $L+W$ & no & 1 wk & T/ Bou & $\mathrm{Hrs}+\min$ \\
\hline Q (5) & $L+T r+W$ & no & 1 wk & $\mathrm{T}$ & $\mathrm{Hrs}+\min$ \\
\hline (2) & W & no & 1 wk & $\mathrm{T} / \mathrm{Br}$ & $\begin{array}{l}\mathrm{Hrs}+\min / \\
\text { freq }\end{array}$ \\
\hline $\mathrm{Q}(2)$ & $\begin{array}{l}\text { Qa: H, L } \\
\text { Qb: To }\end{array}$ & $\begin{array}{l}\text { Qa: no } \\
\text { Qb: yes }\end{array}$ & $\begin{array}{l}\text { Qa: } 1 \text { yr } \\
\text { Qb: - }\end{array}$ & $\mathrm{T}$ & $\mathrm{Hrs}+\min$ \\
\hline$(12)$ & $L+T r+W$ & yes & 1 wk & $\mathrm{T}$ & $\mathrm{Hrs}+\min$ \\
\hline $\mathrm{Q}(10)$ & $L+T r+W$ & yes & $7 d$ & $\mathrm{~T}$ & $\mathrm{Hrs}+\min$ \\
\hline$(19)$ & $L+T r+W$ & no & - & T & $\begin{array}{l}\text { Hrs + min / } \\
\text { freq }\end{array}$ \\
\hline Q (14) & $L+T r+W$ & no & - & $\mathrm{T}$ & $\mathrm{Hrs}+\min$ \\
\hline Q (140) & $L+W$ & no & 1 wk & $\mathrm{T}$ & $\mathrm{Hrs}+\min$ \\
\hline Q (63) & $L+T r+W$ & no & 1 wk & $\mathrm{T}$ & $\mathrm{Hrs}+\min$ \\
\hline Q (63) & $L+T r+W$ & no & $1 d$ & $\mathrm{~T}$ & $\mathrm{Hrs}+\min$ \\
\hline Q (18) & $L+T r+W$ & yes & - & $\mathrm{T}$ & $\mathrm{Hrs}+\min (\mathrm{cat})$ \\
\hline Q (20) & $L+T r+W$ & yes & $1 \mathrm{yr}$ & $\mathrm{T} / \mathrm{Br}$ & $\begin{array}{l}\text { Hrs + min } \\
\text { (cat) / freq }\end{array}$ \\
\hline Q (20) & $L+T r+W$ & yes & 1 wk & $\mathrm{T} / \mathrm{Br}$ & $\begin{array}{l}\text { Hrs + min (cat) } \\
/ \text { freq }\end{array}$ \\
\hline Q (17) & $\begin{array}{l}\mathrm{H}+\mathrm{L}+ \\
\mathrm{Tr}+\mathrm{W}\end{array}$ & no & $4 w k$ & $\mathrm{~T}$ & $\mathrm{Hrs}+\min$ \\
\hline Q (13) & $\begin{array}{l}\mathrm{H}+\mathrm{L}+ \\
\mathrm{Tr}+\mathrm{W}\end{array}$ & no & $\begin{array}{l}1 \mathrm{~d} \\
1 \mathrm{wk}\end{array}$ & $\mathrm{T}$ & $\mathrm{Hrs}+\min$ \\
\hline $\mathrm{Q}(10)$ & $L+T r+W$ & yes & $1 w k$ & $\mathrm{~T}$ & $\mathrm{Hrs}+\min$ \\
\hline$Q(10)$ & $L+T r+W$ & yes & 1 wk & $\mathrm{T}$ & $\mathrm{Hrs}+\min$ \\
\hline $\mathrm{Q}(10)$ & $L+T r+W$ & yes & - & $\mathrm{T}$ & $\mathrm{Hrs}+\min$ \\
\hline $\mathrm{Q}(12)$ & $L+T r+W$ & Yes & 1 wk & $\mathrm{T}$ & $\mathrm{Hrs}+\min (\mathrm{cat})$ \\
\hline $\mathrm{Q}(10)$ & $L+T r+W$ & yes & - & $\mathrm{T}$ & $\mathrm{Hrs}+\min$ \\
\hline $\mathrm{Q}(12)$ & $L+T r$ & no & 1 wk & $\mathrm{T}$ & $\mathrm{Hrs}+\min$ \\
\hline $\mathrm{Q}(20)$ & $L+T r+W$ & no & - & $\mathrm{T}$ & $\mathrm{Hrs}+\min$ \\
\hline L & $L+T r+W$ & yes & $1 \mathrm{~d}$ & $\mathrm{~T}$ & $\mathrm{Hrs}+\min$ \\
\hline D & To & no & - & $\mathrm{T}$ & $\mathrm{Hrs}+\min$ \\
\hline D & $L+T r+W$ & no & $1 \mathrm{~d}$ & $\mathrm{~T}$ & $\mathrm{Hrs}+\min$ \\
\hline & $L+T r+W$ & no & $1 \mathrm{~d}$ & $\mathrm{~T}$ & $\mathrm{Hrs}+\min$ \\
\hline
\end{tabular}


Table 1 Description of measurement tools to determine sedentary behaviour (Continued)

\begin{tabular}{|c|c|c|c|c|c|c|}
\hline \multirow[t]{2}{*}{ Name of tool (reference) } & \multirow{2}{*}{$\begin{array}{l}\text { Specific } \\
\text { tool (no. of } \\
\text { questions) }^{\mathbf{a}}\end{array}$} & \multicolumn{3}{|l|}{ Construct } & \multirow[t]{2}{*}{ Format $^{c}$} & \multirow[t]{2}{*}{ Unit } \\
\hline & & Domain $^{\mathbf{b}}$ & $\begin{array}{l}\text { Distinction in } \\
\text { days (wk/wknd; } \\
\text { work days) }\end{array}$ & $\begin{array}{l}\text { Recall } \\
\text { period }\end{array}$ & & \\
\hline EMA; Ecological Momentary Assessment [93] & $\mathrm{D}$ & To & no & $1 d$ & $\mathrm{~T}$ & $\mathrm{Hrs}+\min (\mathrm{cat})$ \\
\hline MARCA; Multimedia Activity Recall for Children and Adults $[32,94]$ & । & $L+T r+W$ & no & $1 d$ & $\mathrm{~T}$ & $\mathrm{Hrs}+\mathrm{min}$ \\
\hline PAMS; Physical Activity Measurement Survey [95] & । & $L+\operatorname{Tr}+W$ & no & $1 d$ & $\mathrm{~T}$ & $\mathrm{Hrs}+\min$ \\
\hline PDR; Previous Day Recall [45] & 1 & $L+\operatorname{Tr}+W$ & no & $1 d$ & $\mathrm{~T}$ & $\mathrm{Hrs}+\min$ \\
\hline Time Use Survey [96] & D & $L+\operatorname{Tr}+W$ & no & $1 d$ & $\mathrm{~T}$ & $\mathrm{Hrs}+\min$ \\
\hline Updated PDR; Updated Previous Day Recall [97] & । & $L+T r+W$ & no & $1 d$ & $\mathrm{~T}$ & $\mathrm{Hrs}+\min$ \\
\hline
\end{tabular}

${ }^{\mathrm{a}} \mathrm{Q}=$ questionnaire; $\mathrm{L}=\log ; \mathrm{D}=$ diary; I = interview

${ }^{\mathrm{b}} \mathrm{To}=$ Total; $\mathrm{H}=$ Household; $\mathrm{L}=$ Leisure; $\mathrm{Tr}=$ Transport; $\mathrm{W}=$ Work

${ }^{\mathrm{C}} \mathrm{T}=$ Total time; $\mathrm{Br}=$ breaks; $\mathrm{Bou}=$ bouts

participants, 3) gender and age, 4) the construct of SB measured (domain, setting, recall period, number of questions), 5) measurement outcomes (e.g. total sedentary time, breaks in sitting time, bouts), 6) comparison measure when validity was assessed, 7) interval between first and second measure when reliability was assessed, and 8) results of the measurement properties (e.g. intra correlation coefficients [ICC], correlations, mean bias with limits of agreement, kappa values and sensitivity/ specificity). The extraction form was created by one (EB) and piloted by both reviewers $(\mathrm{EB}, \mathrm{YH})$. The pilot was performed using 10 randomly selected studies and changes were made to improve the extraction form. The quality of the studies was determined using the checklist with 4-point scale of COSMIN (Consensus-based Standards for the selection of health Measurement Instruments) criteria [99-101]. The COSMIN checklist contained items about the criterion validity (Additional Table 2) and reliability (Additional Table 3). For each item different design requirements and statistical methods were rated on quality using a 4-point scale. A methodological quality score per item was obtained by taking the lowest rating of any score per item ('worse score counts') [101].

\section{Assessment of construct validity and reliability}

Criterion validity was defined as the degree to which the outcome measure measures the construct it purposes to measure [103]. Thigh-worn accelerometry (e.g. activPAL) was considered as the gold standard for total sedentary time, as they can more accurately distinguish between sitting and standing [11]. Hip-, waist- and wrist-worn accelerometers are frequently used as criterion measure. However, these accelerometers are not sensitive enough to distinguish between stationary standing and sitting [104]. On these grounds, studies using only hip-, waist- and wristworn accelerometers as criterion measure were graded with a lower level of evidence. In addition, if validity results of both thigh-worn accelerometers or hip-, waist- and wrist-worn accelerometers were included in the study, only the results of the thigh-worn accelerometers were reported in this review.

Reliability was defined as the degree of consistency and reproducibility of a measurement tool. Test-retest reliability is often assessed using an ICC [103]. Since Pearson and Spearman correlation coefficients neglect systematic errors, the use of Pearson and Spearman correlation coefficient was considered as inadequate and these studies were graded with a lower level of evidence. In addition, if studies provided both ICCs and correlation coefficients, only ICCs were reported in this review. An ICC $>0.90$ was considered as excellent, ICC between $0.75-0.90$ was considered as good, ICC between $0.50-0.75$ as moderate and $>0.50$ as poor [105].

\section{Data analyses}

A meta-analysis using random effects [106] was performed to assess the pooled validity of the 1-item questionnaires, 2 to 9 -item questionnaires, $\geq 10$-item questionnaires and logs/diaries. A random effect model was used because it was unlikely that included studies were functional equivalent and results of the included studies had a large heterogeneity. Only studies expressing validity as Pearson or Spearman correlation coefficients were included in this analysis. When no correlation coefficient was provided for total sedentary time, an (unweighted) mean was calculated based on correlation coefficients of all setting and domains. Finally, $\mathrm{I}^{2}$ was calculated, which describes the proportion of total variation in effect size that was due to systematic differences between effect sizes rather than by chance [106]. Stratified analyses including only studies examining questionnaires with a good-to-excellent quality were performed to investigate if the quality of the study affected the pooled validity. Meta-analyses were performed using $R$ with 


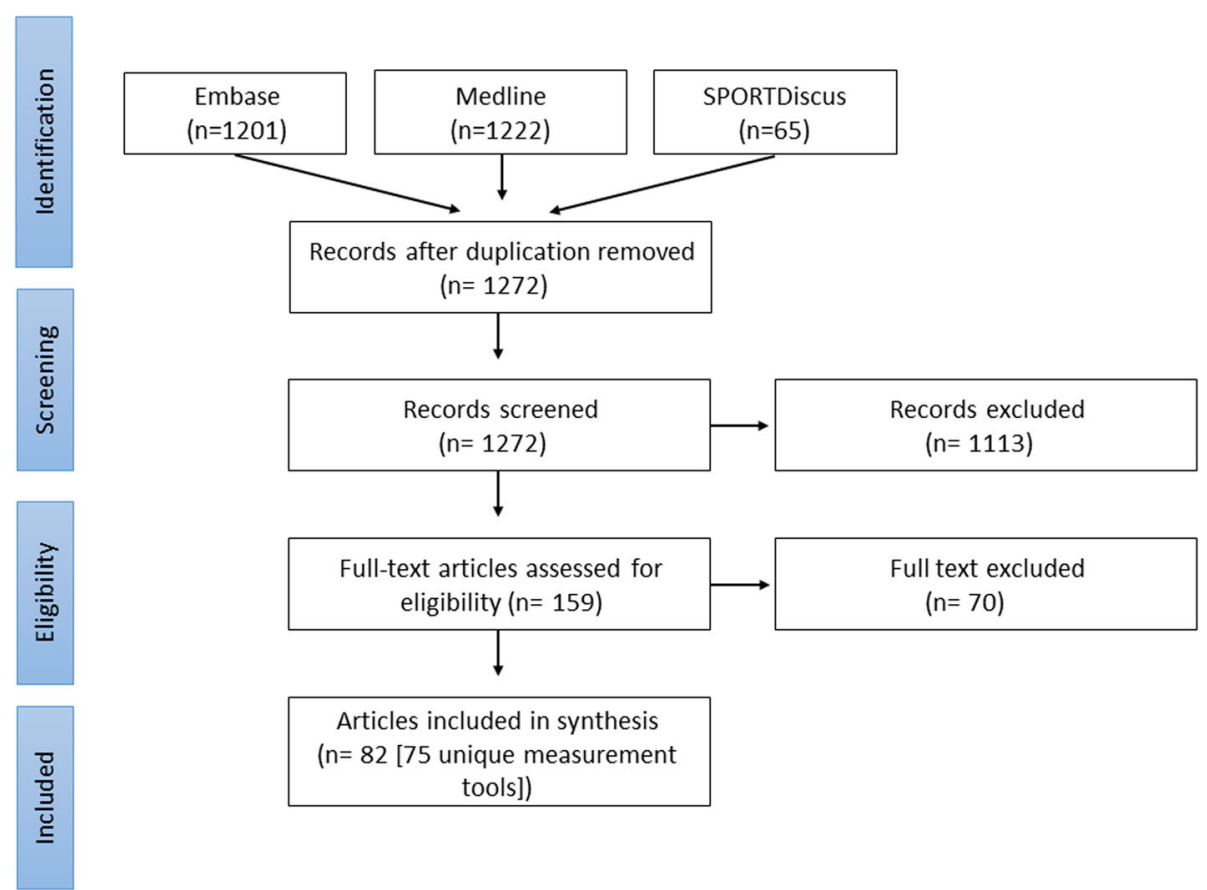

Fig. 1 Flowchart of the inclusion of studies

'Meta-Analysis with Correlations' (MAc) package, version 1.1.1.

\section{Results}

\section{Search results}

The literature search resulted in 2423 hits (Fig. 1). After excluding duplicates, 1272 studies were screened for title and abstract. Most papers were not eligible for this review because: $i$. the articles did not aim to determine SB, ii. no measurement properties were assessed, and/or iii. The study was performed in children or diseased populations. In total 82 studies and 75 self-reported measurement tools were included (Table 1).

\section{Attributes of the questionnaires, logs and diaries}

The majority of the subjective measures were questionnaires and contained different domains and settings of SB (Table 2). Measurement tools differed regarding the timing (week vs weekend), recall period and number of questions. Nearly all self-reported measurement tools expressed SB in total sitting time (hrs/day or hrs/week). The PASB-Q, SITBRQ, SIT-Q, SIT-Q-7d, TASST and several other questionnaires $[31,54,61,67,69,71,78$, 79] included total sitting time, but also information about sitting bout duration or breaks in sitting time.

\section{Validity}

A total of 80 studies examined the validity of one or more methods to assess $\mathrm{SB}$, resulting in a comparison of 96 unique methods (Table 2). Of the 96 results, 5 were ranked with an excellent quality of the study, 7 studies with a good quality, 9 with a fair quality and 75 with a poor quality. The most important shortcoming of the validation studies was the use of an accelerometer $(n=62)$ to examine criterion validity of the method to assess SB. A total of 29 studies used the gold standard approach (thigh-worn accelerometer), three studies used diaries/logs and one used direct observation to assess construct validity. Most studies calculated correlation coefficients between the criterion measure and the self-reported questionnaire, which ranged between -0.01 to 0.90 for total sedentary time and ranged between 0.02 to 0.39 for number of sedentary bouts or breaks (Table 3). Other studies used ICCs $(N=8)$, kappa values $(N=2)$, and sensitivity and specificity outcomes $(N=1)$ to determine the validity, and some added Bland-Altman plots with a mean difference and limits of agreement to examine the accuracy of the method to assess $\mathrm{SB}$ $(N=48)$. Figure 2a provides an overview of the correlation coefficient of all individual studies combined with the quality of the study.

\section{Meta-analyses}

The correlation coefficients of logs and diaries (correlation coefficient estimate $[R]=0.63$ [95\% CI 0.48-0.78], $\left.I^{2}: 95 \%\right)$ were substantially higher than the coefficients of the questionnaires $\left(R=0.35 \quad\left[\begin{array}{llll}95 \% & C I & 0.32-0.39\end{array}\right], \mathrm{I}^{2}\right.$ : 


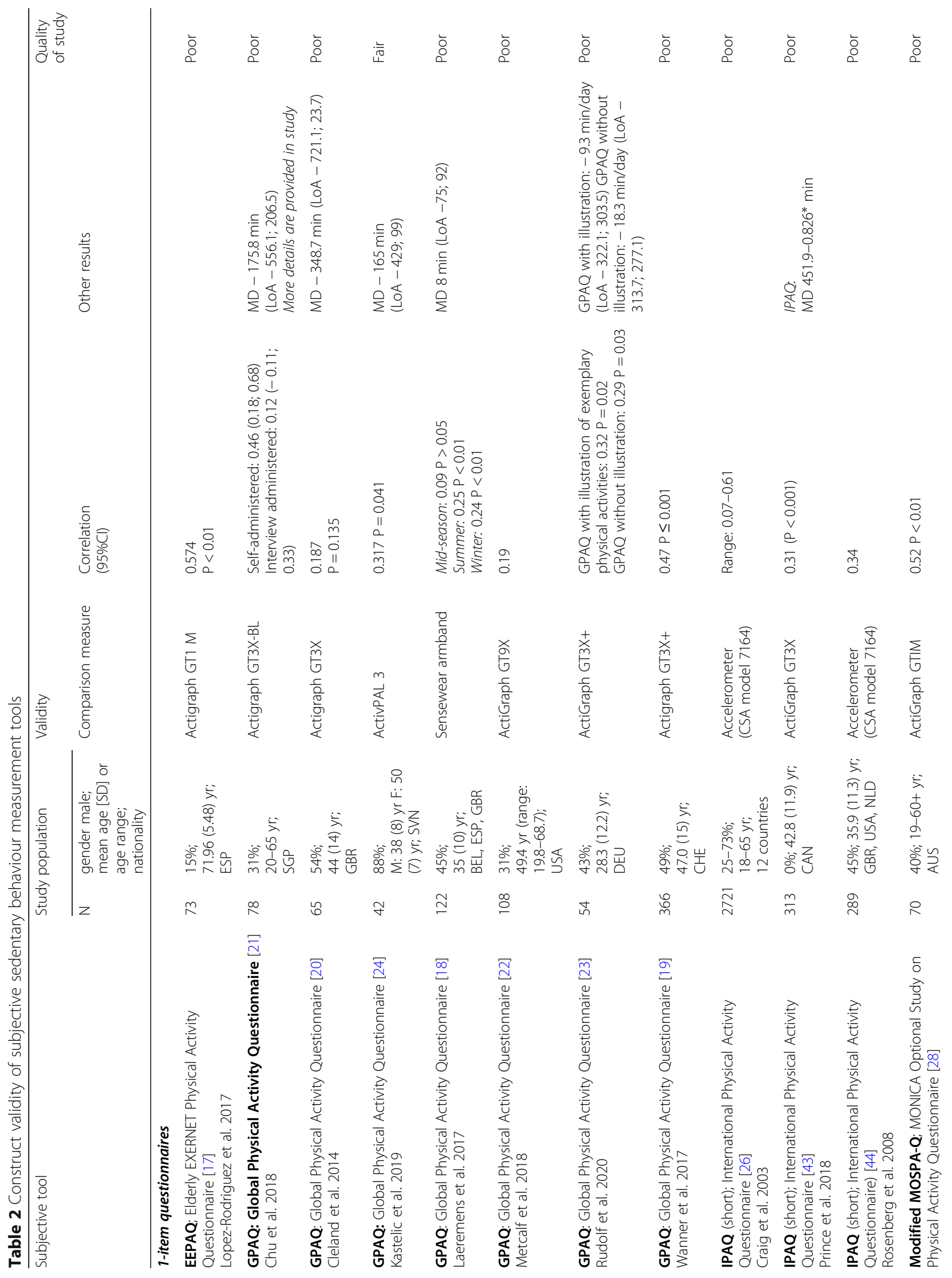




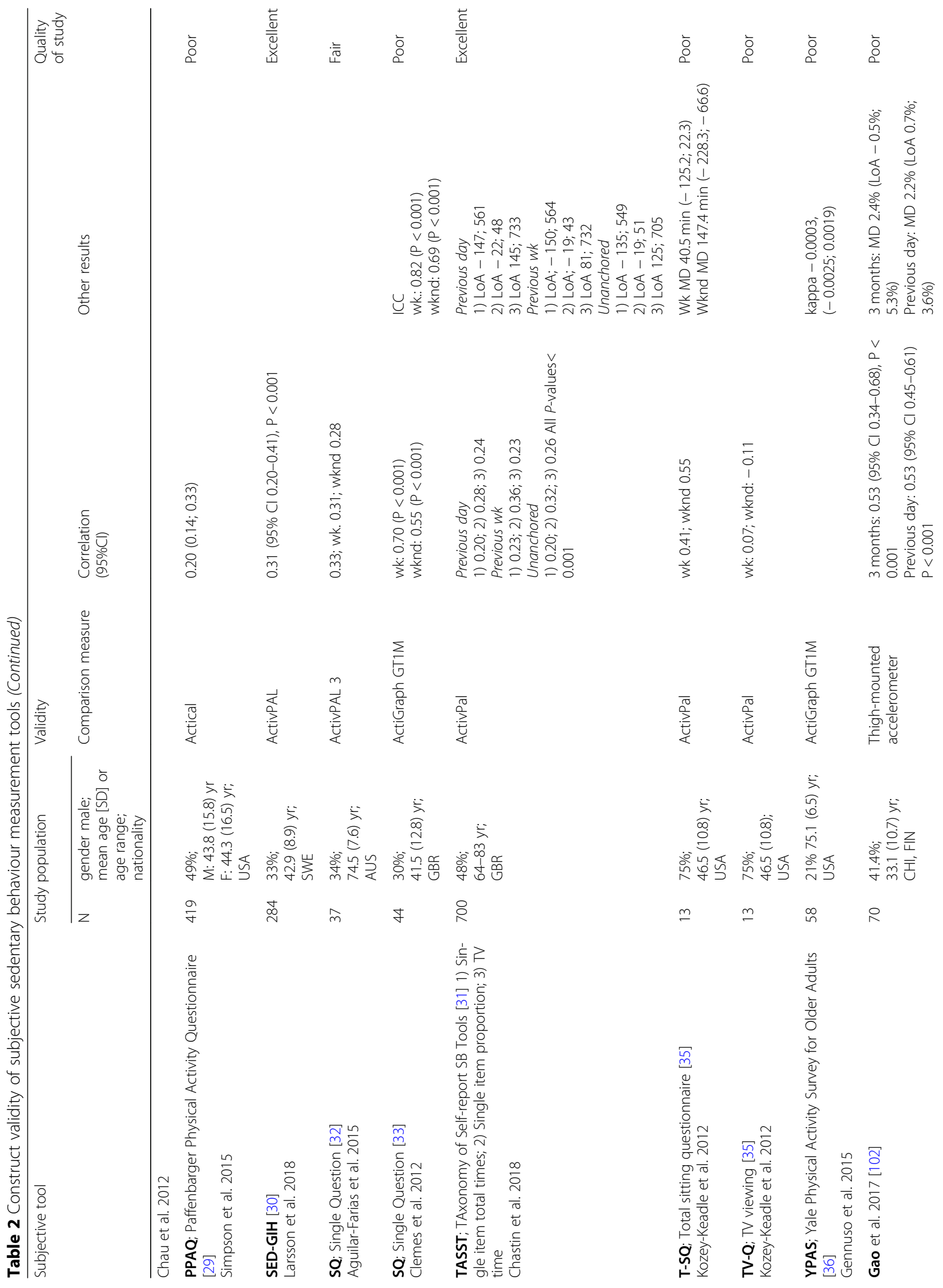




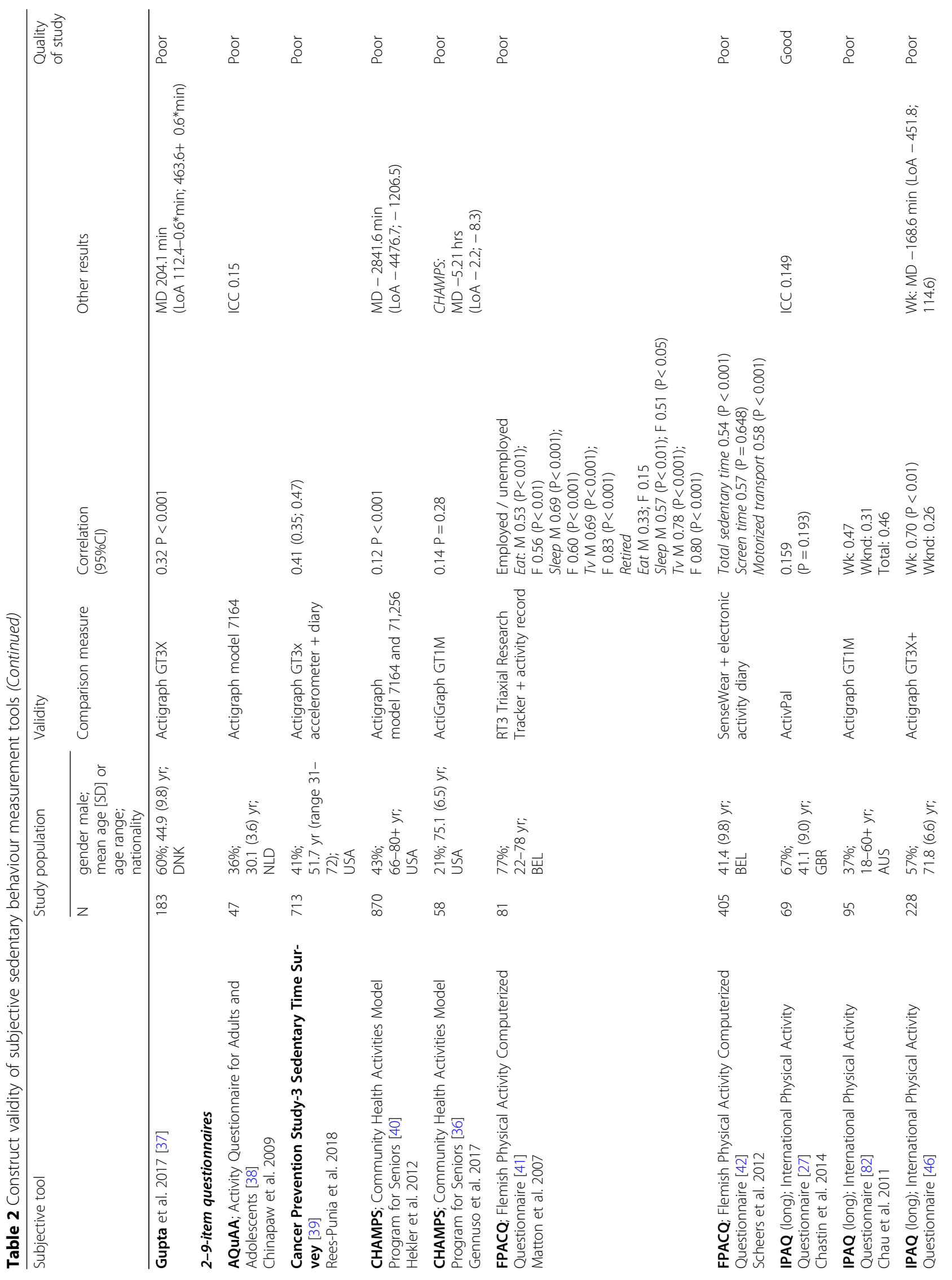




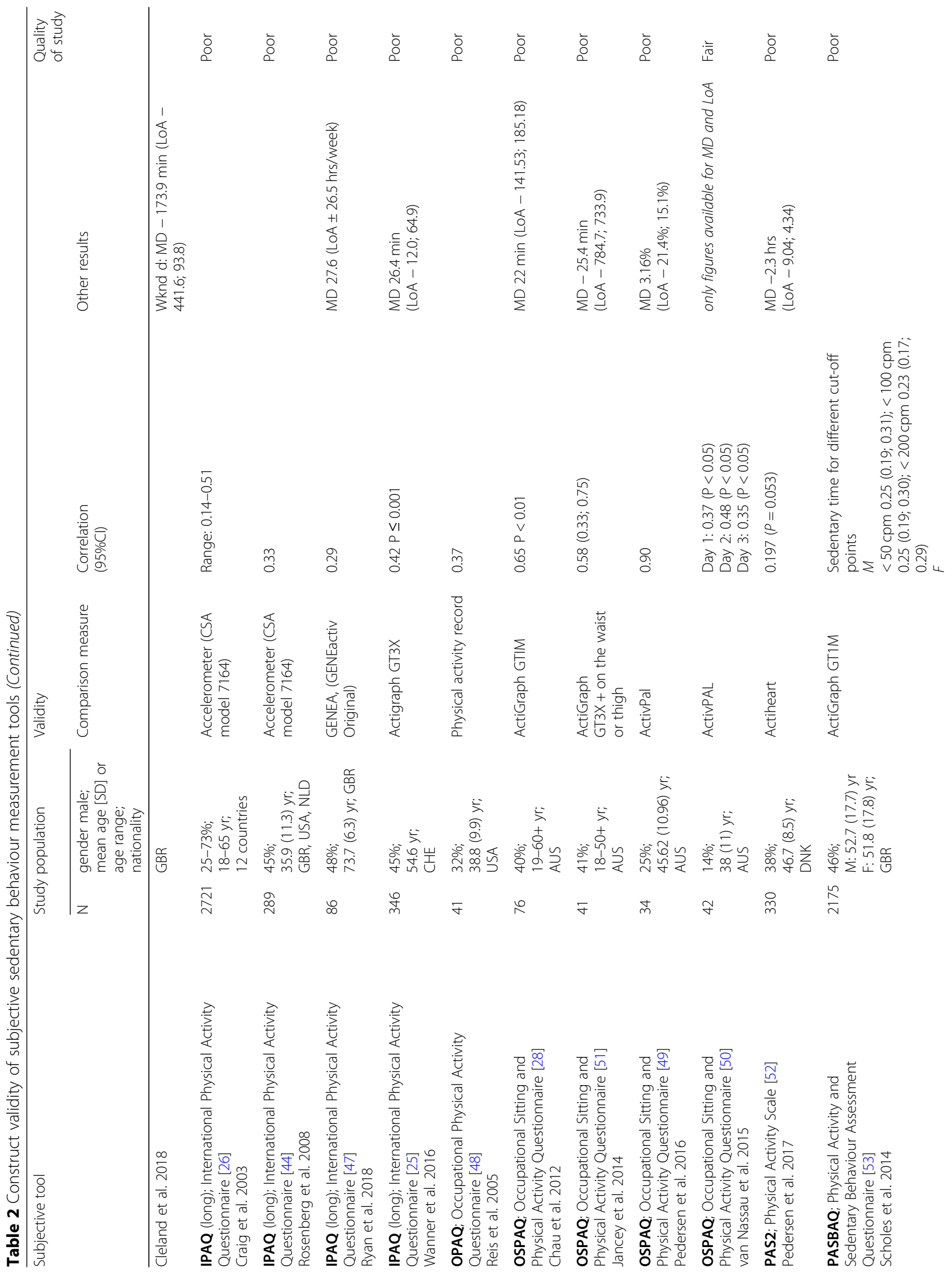




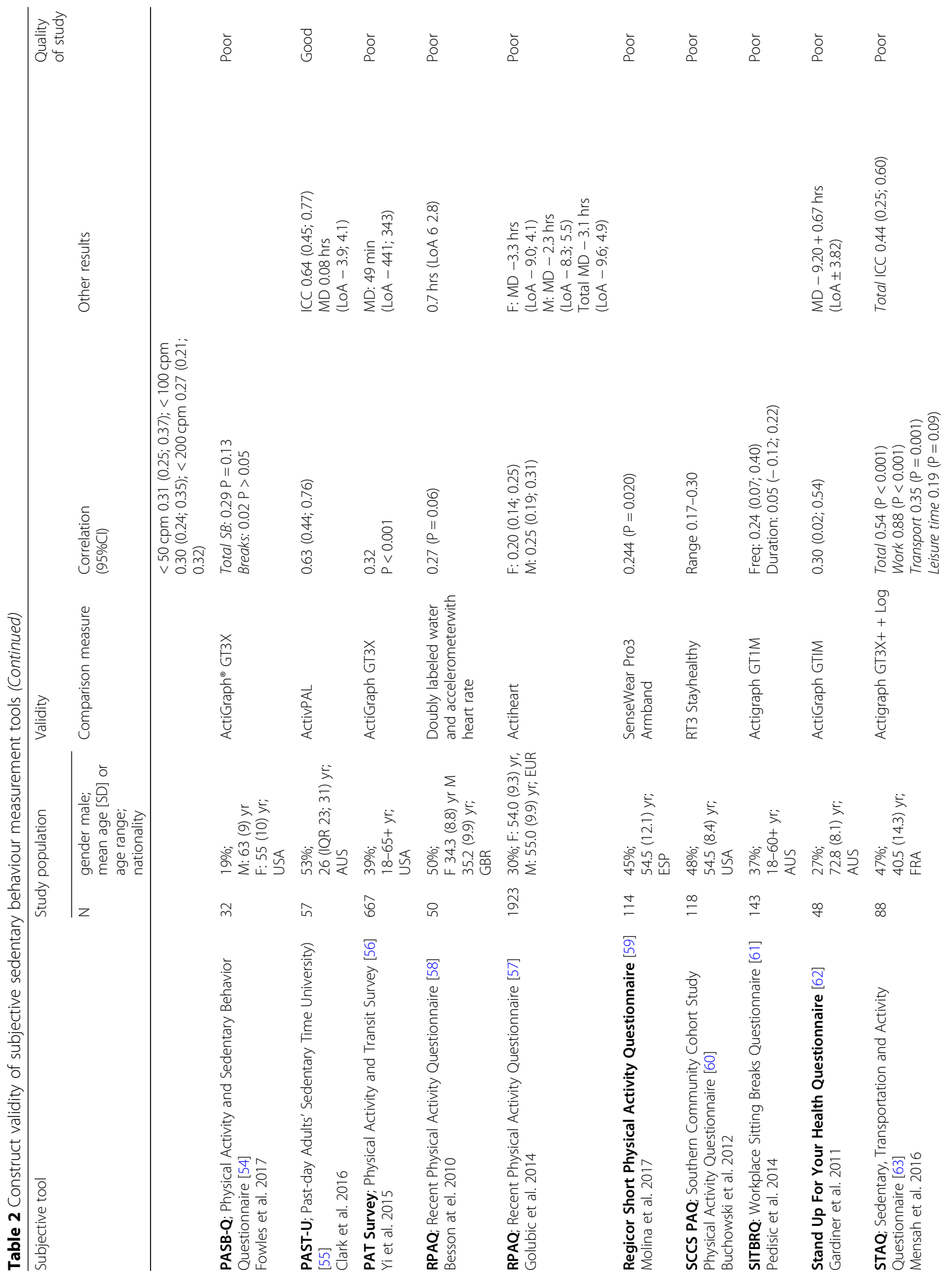




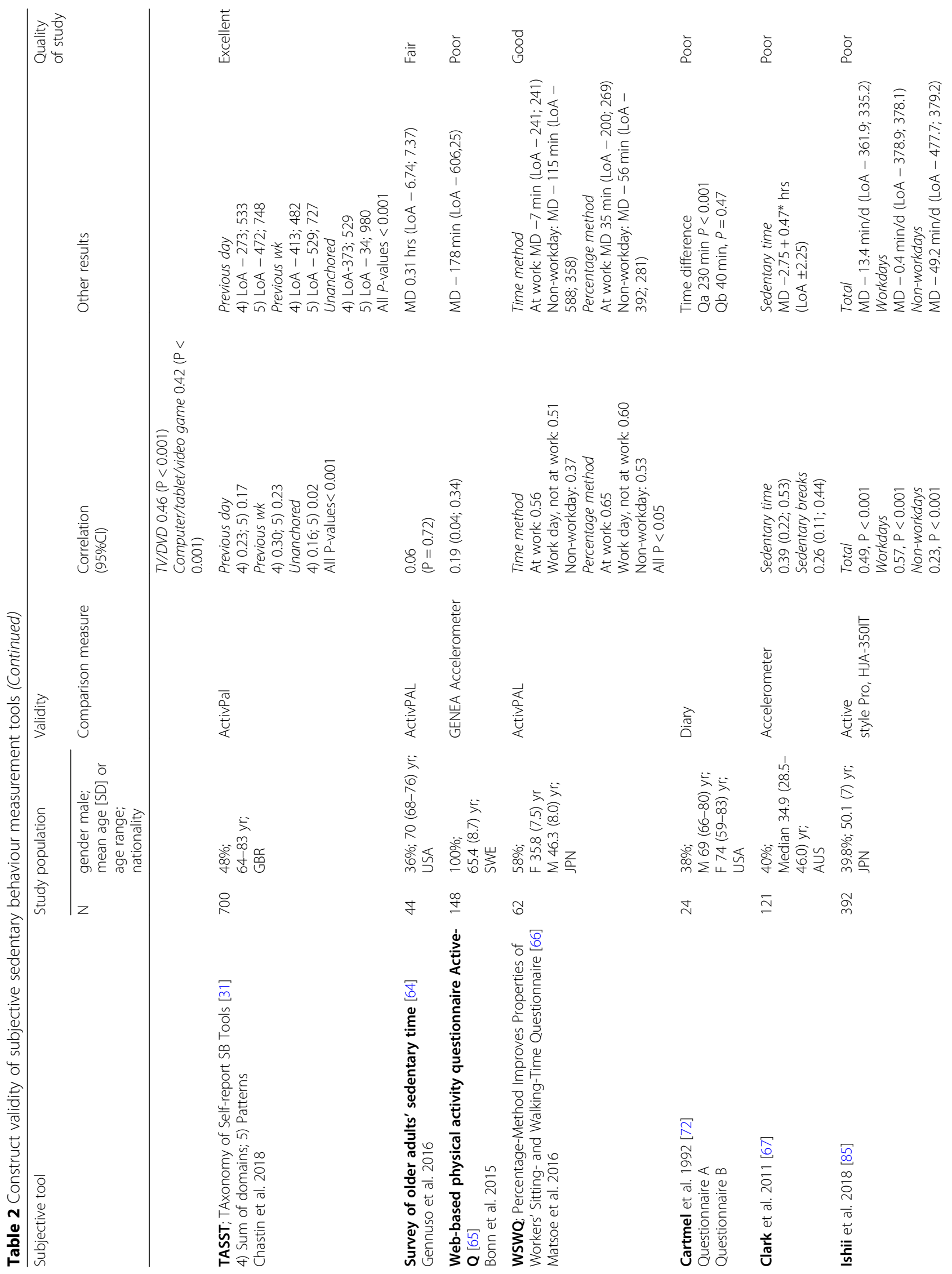




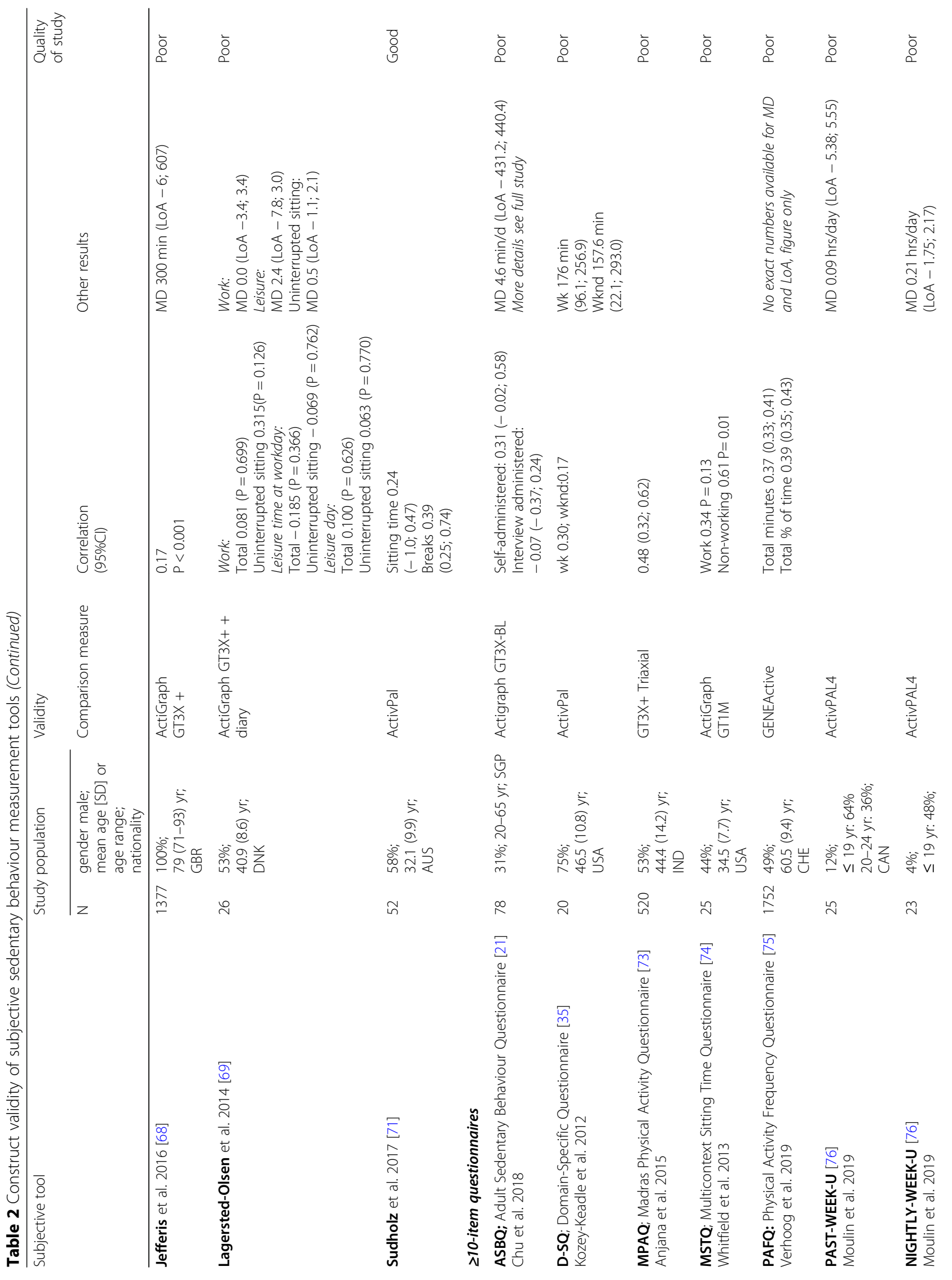




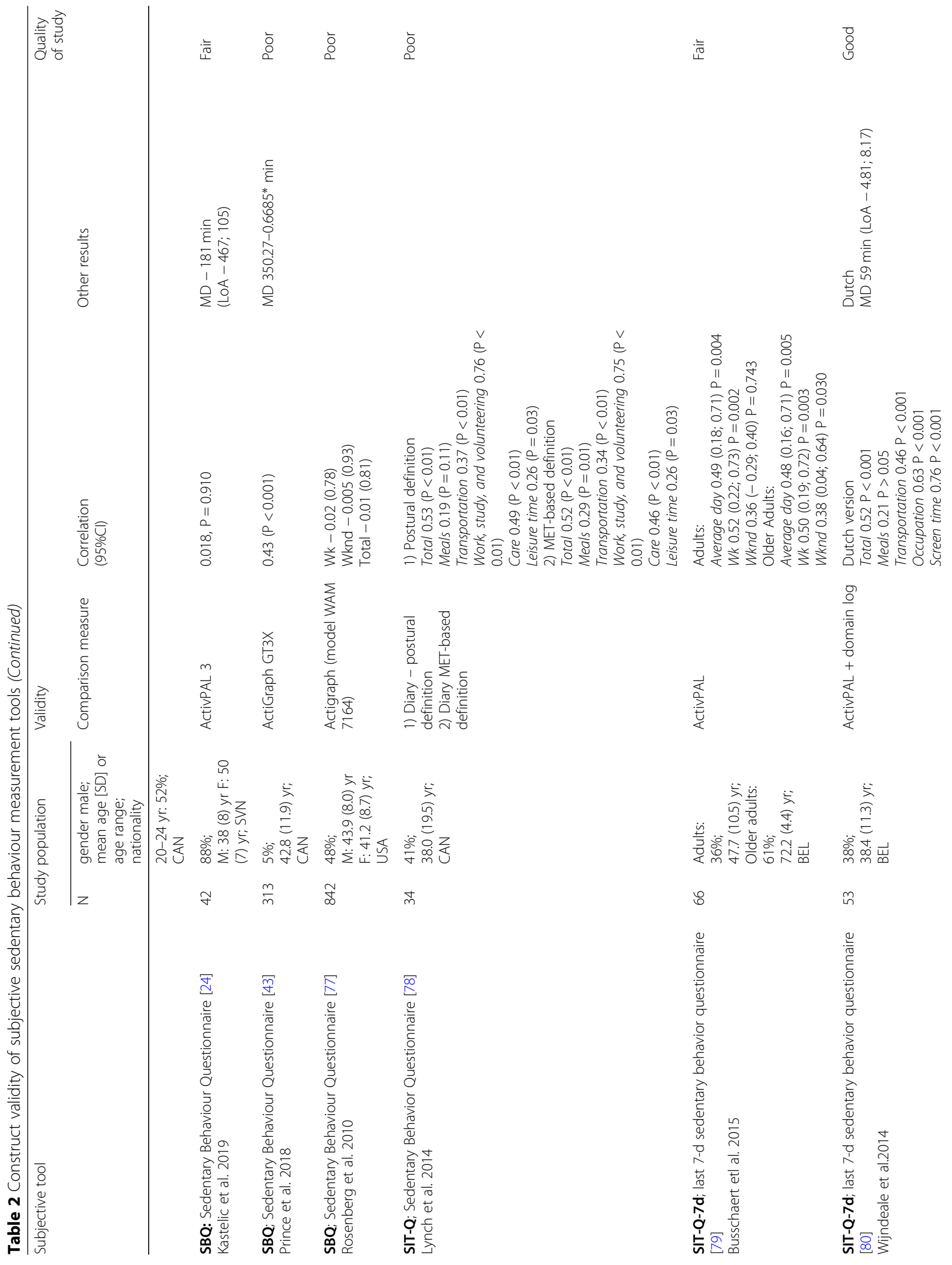




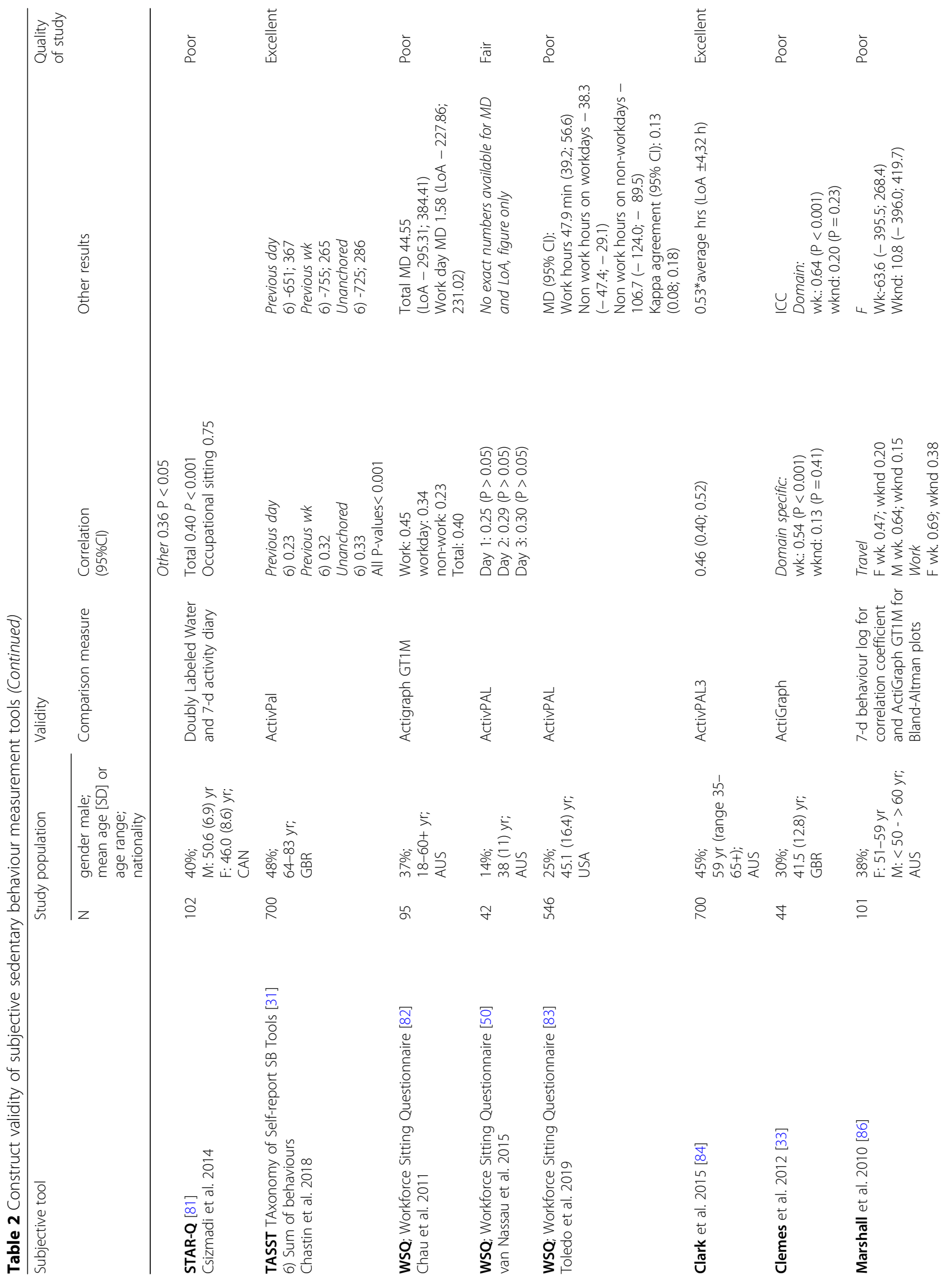


Baker et al. International Journal of Behavioral Nutrition and Physical Activity

(2020) 17:75

Page 16 of 31

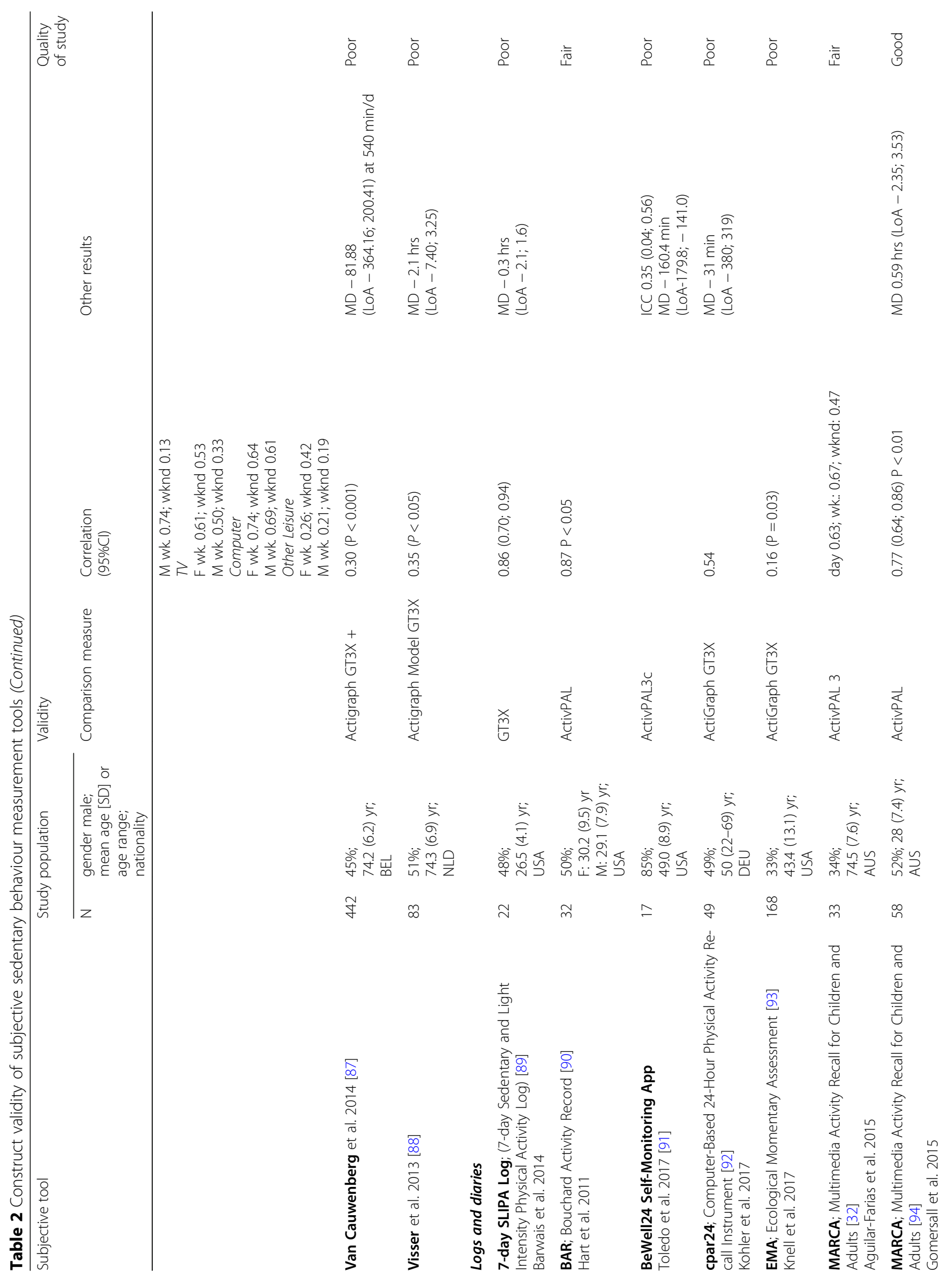




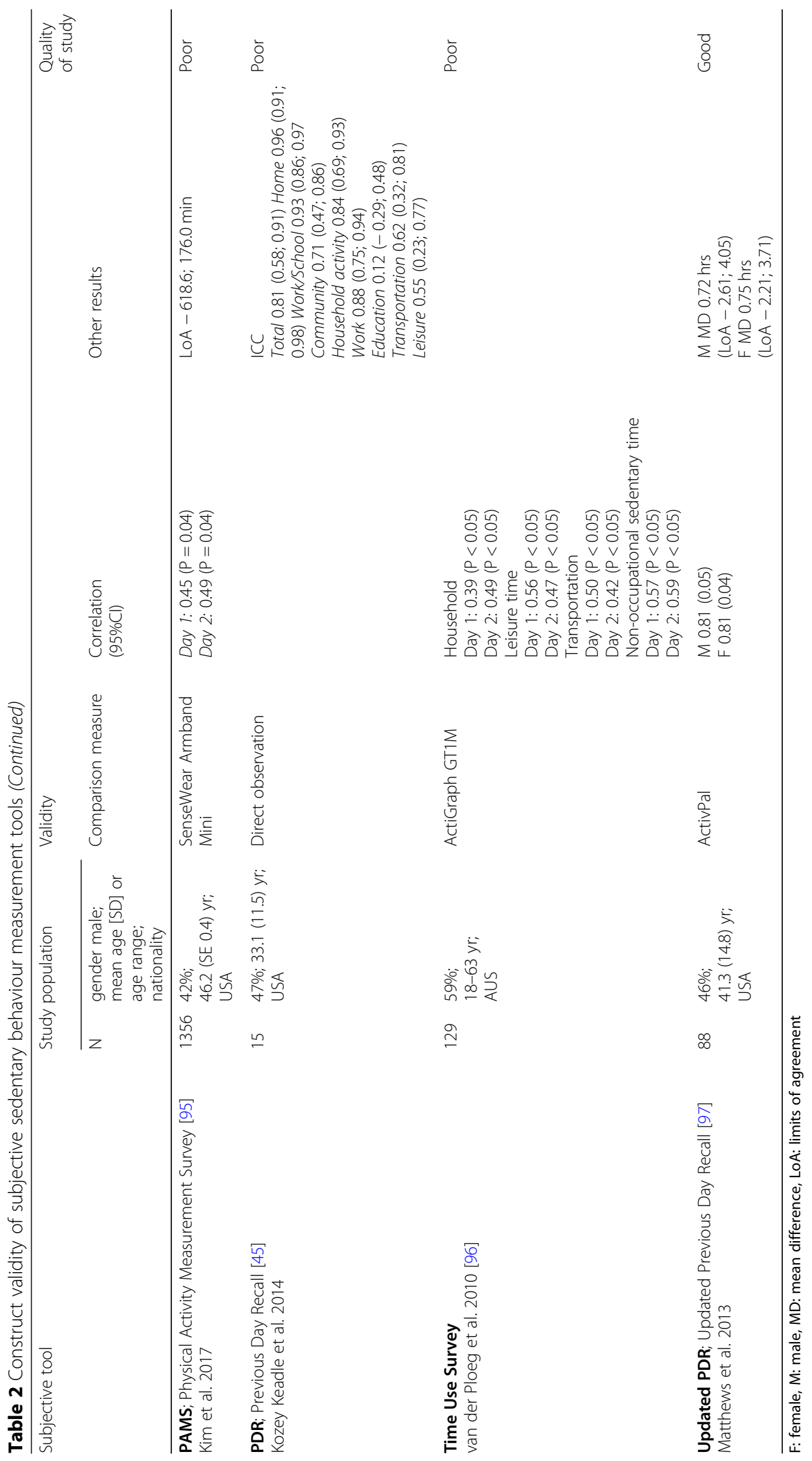




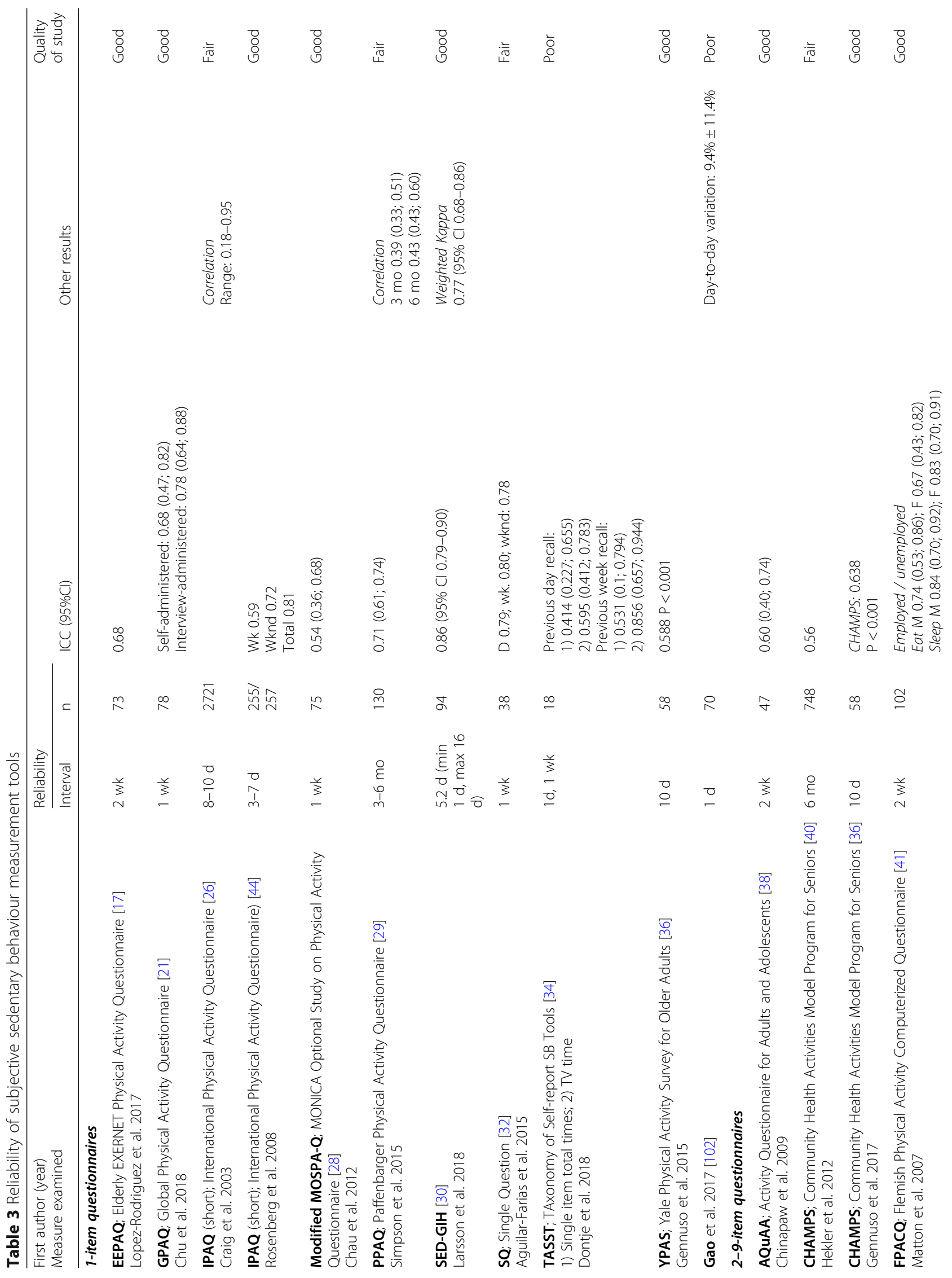




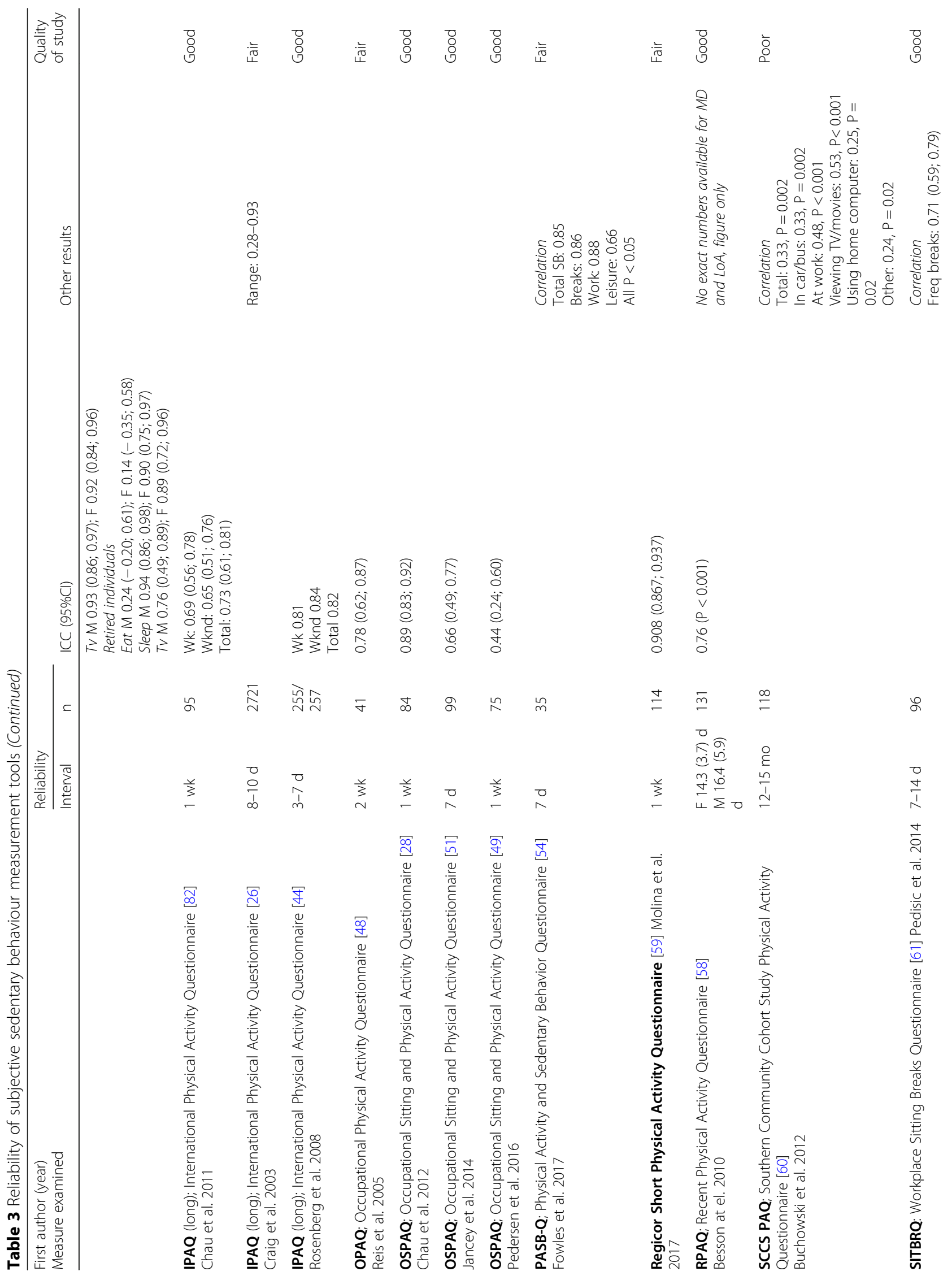




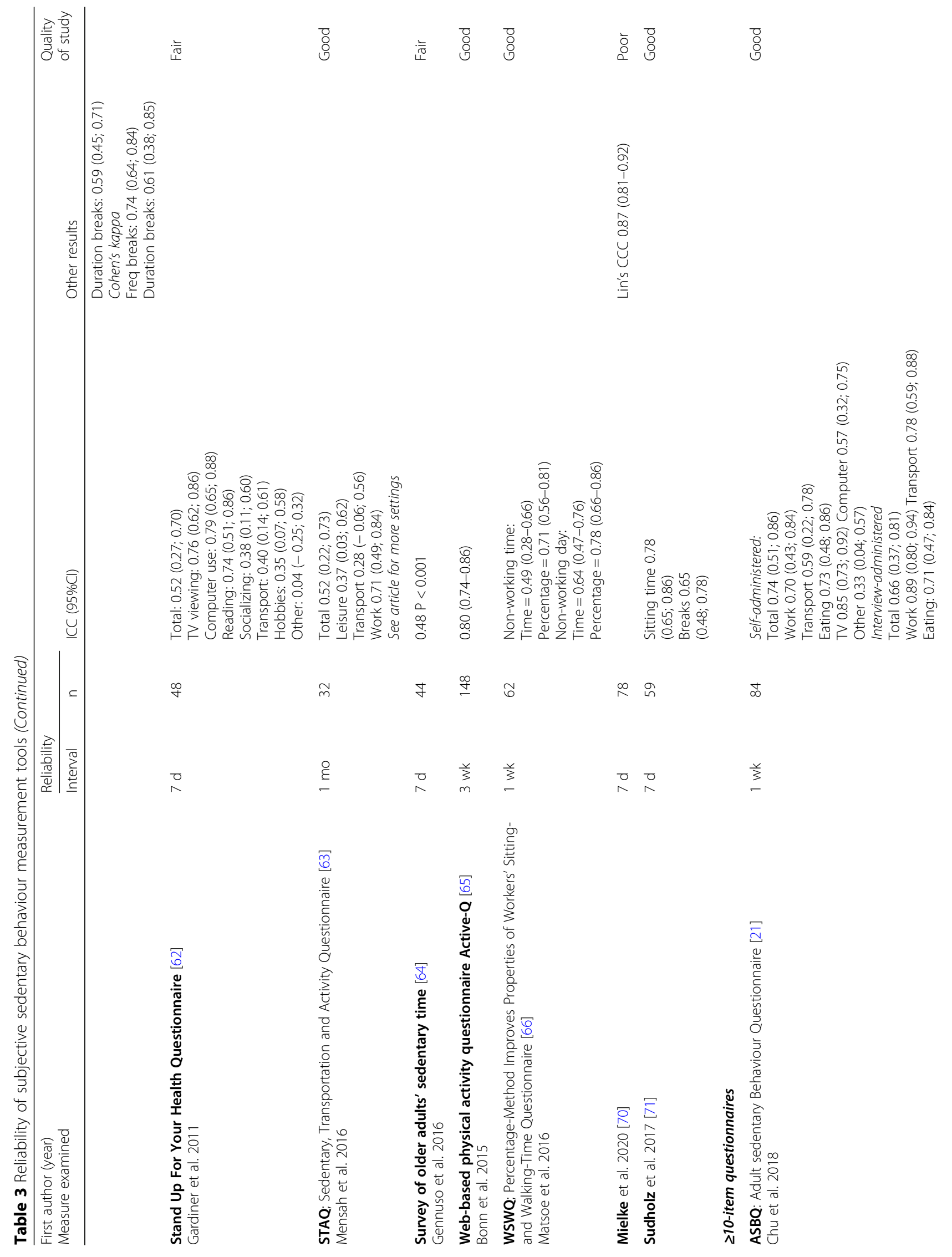




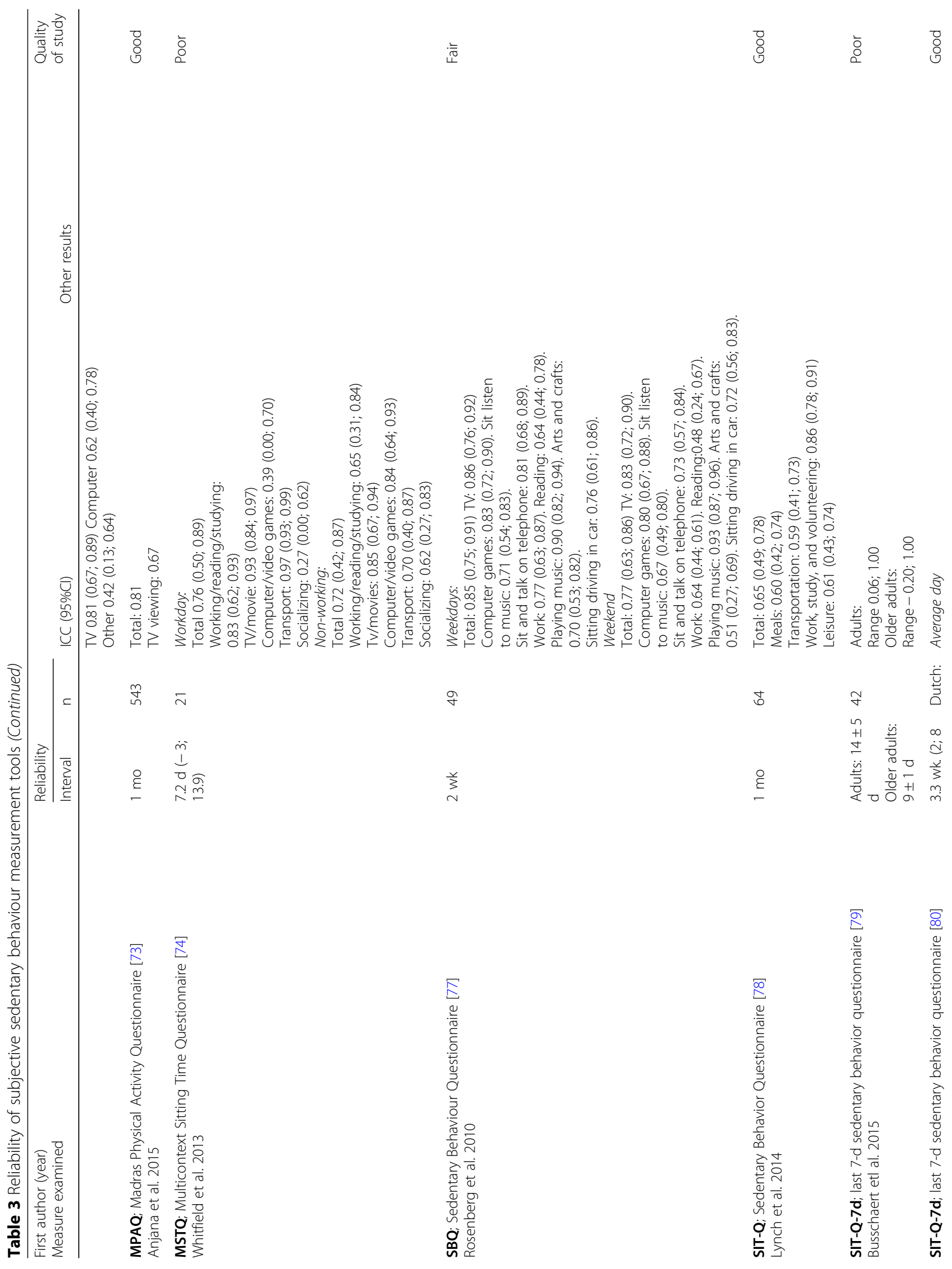




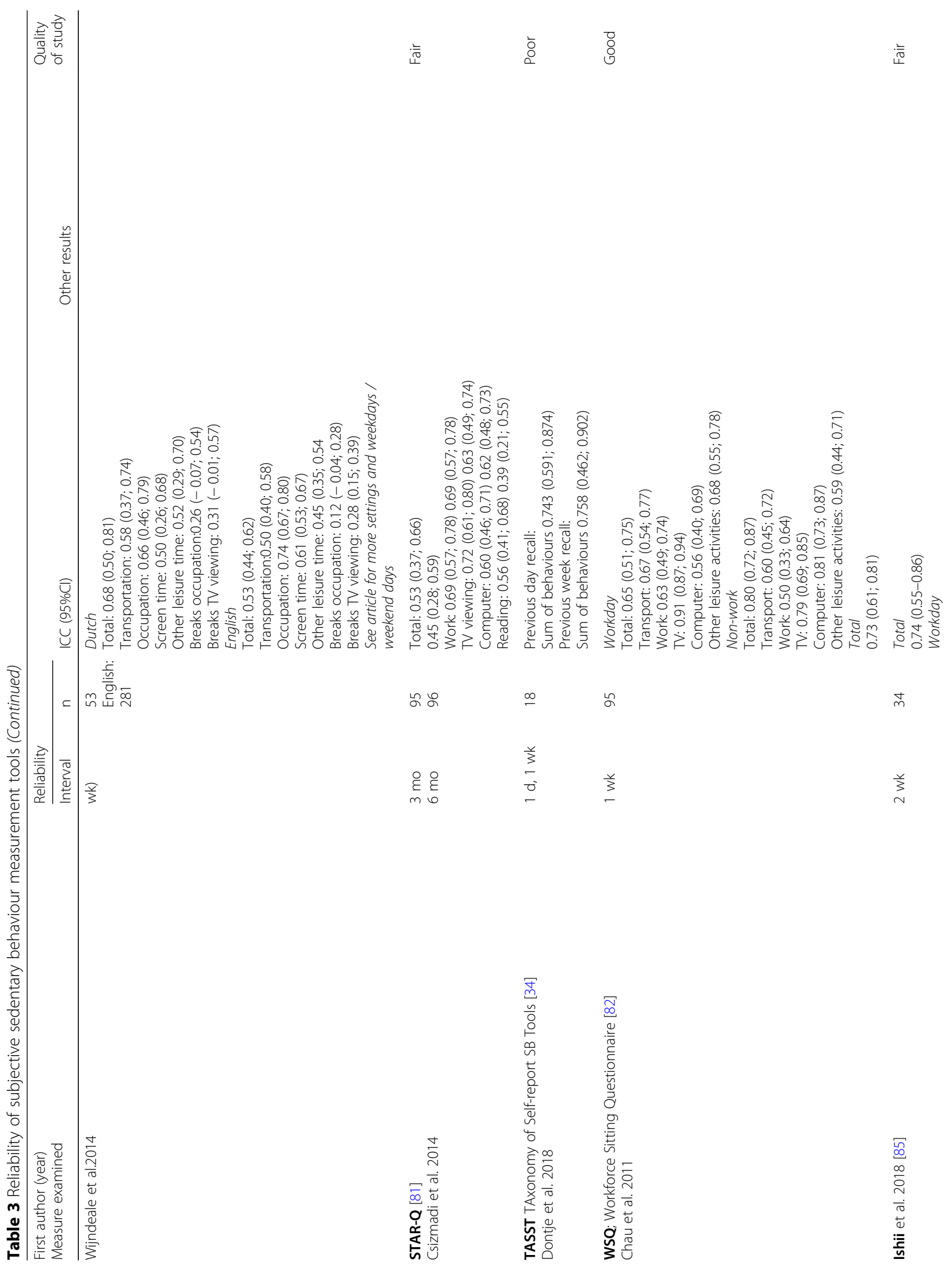




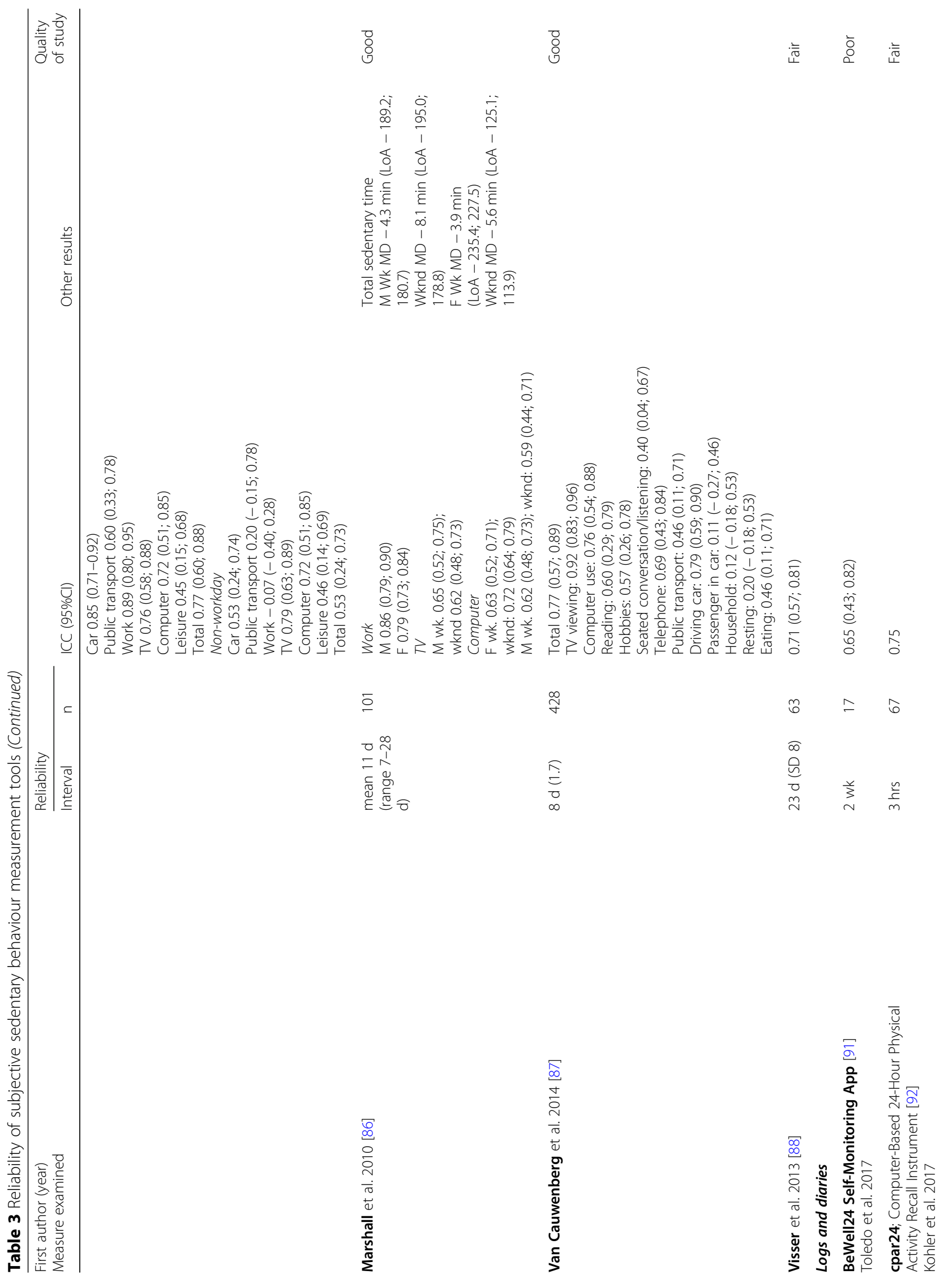




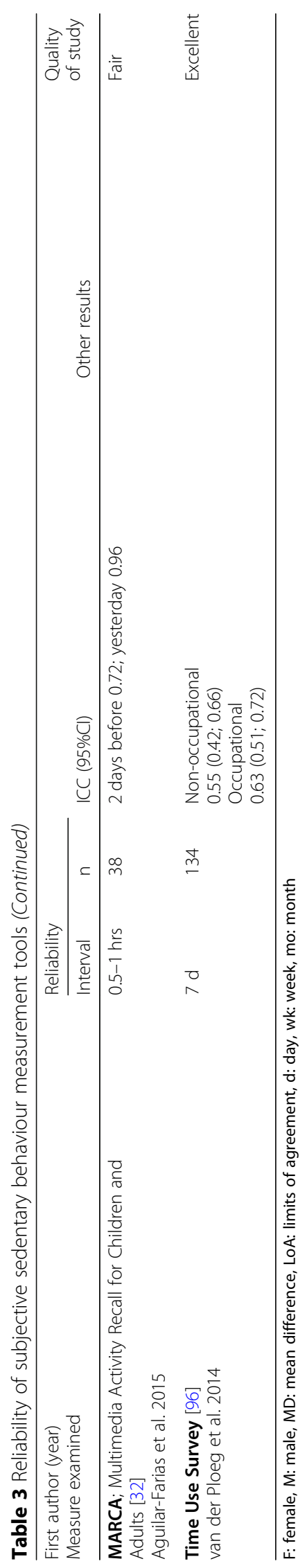




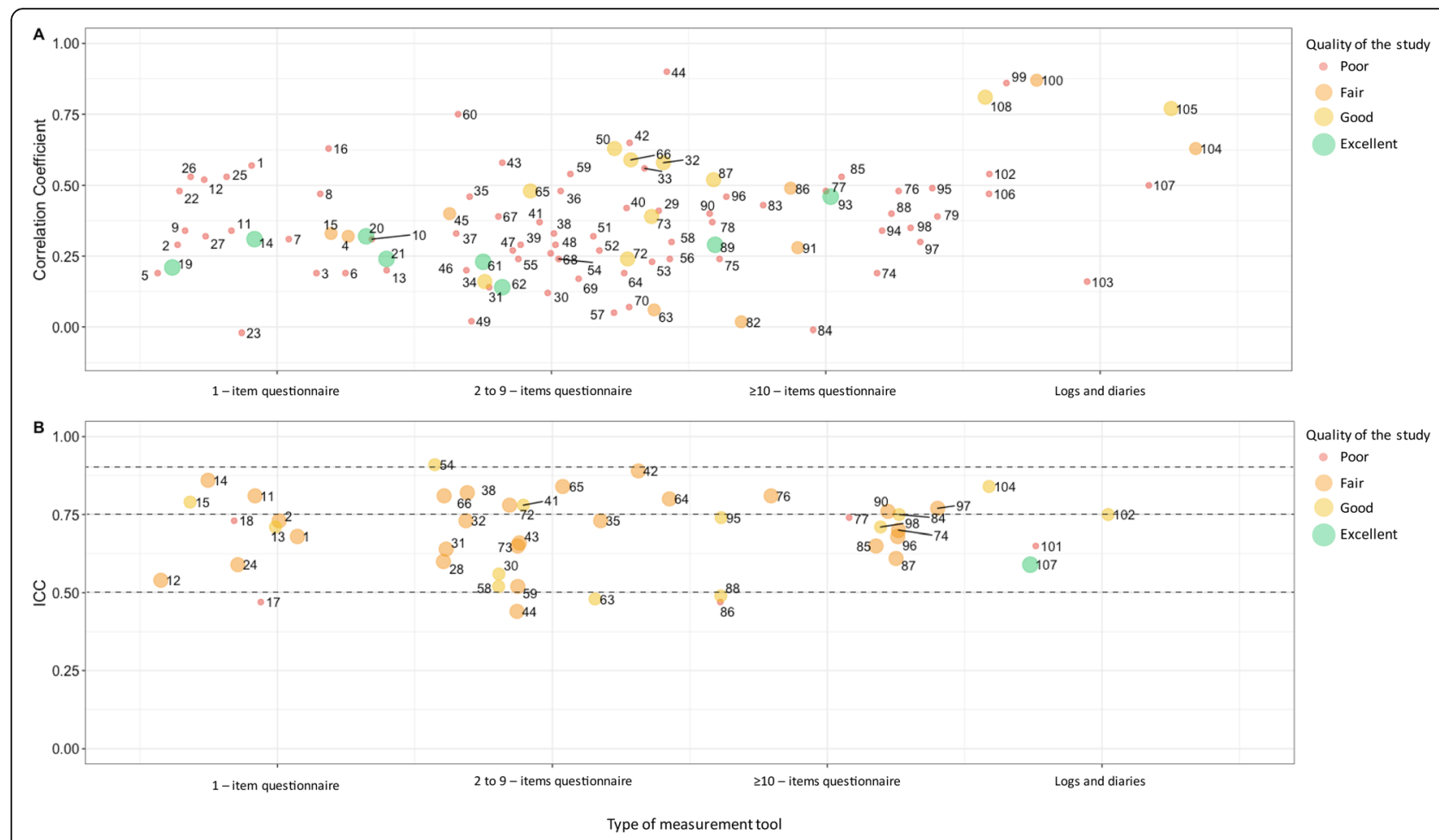

Fig. 2 Overview of construct validity (a) and test retest reliability (b). 1 EEPAQ, Lopez-Rodriguez et al. 2017; 2 GPAQ, Chu et al. 2018; 3 GPAQ, Cleland et al. 2014; 4 GPAQ, Kastelic et al. 2019; 5 GPAQ, Laeremens et al. 2017; 6 GPAQ, Metcalf et al. 2018; 7 GPAQ, Rudolf et al. 2020; 8 GPAQ, Wanner et al. 2017; 9 IPAQ (short), Craig et al. 2003; 10 IPAQ (short), Prince et al. 2018; 11 IPAQ (short), Rosenberg et al. 2008; 12 Modified MOSPA-Q, Chau et al. 2012; 13 PPAQ, Simpson et al. 2015; 14 SED-GIH „; 15 SQ, Aguilar-Farias et al. 2015 ; 16 SQ, Clemes et al. 2012; 17 TASST Single item total times, Dontje et al. 2018; 18 TASST TV time, Dontje et al. 2019; 19 TASST Single item total times, Chastin et al. 2018; 20 TASST Single item proportion, Chastin et al. 2018; 21 TASST TV time, Chastin et al. 2018; 22 T-SQ, Kozey-Keadle et al. 2012; 23 TV-Q, Kozey-Keadle et al. 2012; 24 YPAS, Gennuso et al. 2015; 25 Single item proportion (3 months), Gao et al. $2017 ; 26$ Single item proportion (1 day), Gao et al. 2017; 27 Gupta et al. 2017 [29]; 28 AQuAA, Chinpaw et al. 2009; 29 Cancer Prevention Study-3 Sedentary Time Survey, Rees-Punia et al. 2018; 30 CHAMPS, Hekler et al. 2012; 31 CHAMPS, Gennuso et al. 2017; 32 FPACQ, Matton et al. 2007; 33 FPACQ, Scheers et al. 2012; 34 IPAQ (long), Chastin et al. 2014; 35 IPAQ (long), Chau et al. 2011; 36 IPAQ (long), Cleland et al. 2018; 37 IPAQ (long), Craig et al. 2003; 38 IPAQ (long), Rosenberg et al. 2008; 39 IPAQ (long), Ruan et al. 2018; 40 IPAQ (long), Wanner et al. 2016; 41 OPAQ, Reis et al. 2005; 42 OSPAQ, Chau et al. 2012; 43 OSPAQ, Jancey et al. 2014; 44 OSPAQ, Pedersen et al. 2016; 45 OSPAQ, van Nassau et al. 2015; 46 PAS2, Pedersen et al. 2017; 47 PASBAQ, Scholes et al. 2014; 48 PASB-Q total SB, Fowles et al. $2017 ; 49$ PASB-Q breaks, Fowles et al. 2017; 50 PAST-U, Clark et al. 2016; 51 PAT Survey, Yi et al. 2015; 52 RPAQ, Besson at el. 2010; 53 RPAQ, Golubic et al. 2014; 54 Regicor Short Physical Activity Questionnaire [47] Molina et al. 2017; 55 SCCS PAQ, Buchowski et al. $2012 ; 56$ SITBRQ bout frequency, Pedisic et al. 2014; 57 SITBRQ bout duration, Pedisic et al. 2014; 58 Stand Up For Your Health Questionnaire, Gardiner et al. 2011; 59 STAQ, Mensah et al. 2016; 60 TASST, Sum of domains, Dontje et al. 2018; 61 TASST Sum of domains, Chastin et al. 2018; 62 TASST Patterns, Chastin et al. 2018; 63 Survey of older adults' sedentary time, Gennuso et al. 2016; 64 Web-based physical activity questionnaire Active-Q, Bonn et al. 2015; 65 WSWQ Time method, Matsoe et al. 2016; 66 WSWQ Percentage method, Matsoe et al. 2016; 67 Sedentary time, Clark et al. 2011; 68 Sedentary breaks, Clark et al. 2011; 69 Jefferis et al. 2016; 70 Lagersted-Olsen et al. 2014; 71 Mielke et al. 2020; 72 Sitting time, Sudholz et al. 2017; 73 Sitting breaks, Sudholz et al. 2017; 74 ASBQ, Chu et al. 2018 ; 75 D-SQ, Kozey-Keadle et al. 2012; 76 MPAQ, Anjana et al. 2015; 77 MSTQ, Whitfield et al. 2013; 78 PAFQ sitting time, Verhoog et al. 2019; 79 PAFQ sitting proportion, Verhoog et al. 2019; 80 PAST-WEEK-U, Moulin et al. 2020; 81 NIGHTLY-WEEK-U, Moulin et al. 2020; 82 SBQ, Kastelic et al. 2019; 83 SBQ, Prince et al. 2018; 84 SBQ, Rosenberg et al. 2010; 85 SIT-Q, Lynch et al. 2014; 86 SIT-Q-7d, Busschaert et al. 2015; 87 SIT-Q-7d, Wijndeale et al.2014; 88 STAR-Q, Csizmadi et al. 2014; 89 TASST Chastin et al. 2018; 90 WSQ, Chau et al. 2011; 91 WSQ, van Nassau et al. 2015; 92 WSQ, Toledo et al. 2019; 93 Clark et al. 2015; 94 Clemes et al. 2012; 95 Ishii et al. 2018; 96 Marshall et al. $2010 ; 97$ Van Cauwenberg et al. 2014; 98 Visser et al. 2013 [64]; 99 7-day SLIPA Log, Barwais et al. 2014; 100 BAR, Hart et al. $2011 ; 101$ BeWell24 Self-Monitoring App, Toledo et al. 2017; 102 cpar24, Kohler et al. 2017; 103 EMA, Knell et al. 2017; 104 MARCA, Aguilar-Farias et al. 2015; 105 MARCA, Gomersall et al. 2015; 106 PAMS, Kim et al. 2017; 107 Time Use Survey, van der Ploeg et al. 2014; 108 Updated PDR, Matthews et al. 2013. The studies within each category are place randomly to avoid overlap when they are aligned. An ICC $>0.90$ was considered as excellent, ICC between $0.75-0.90$ was considered as good, ICC between 0.50-0.75 as moderate and >0.50 as poor 
90\%). Furthermore, correlation coefficient estimates of the questionnaires with $\geq 10$-item $(R=0.37 \quad[95 \% \mathrm{CI}$ $\left.0.30-0.43], I^{2}: 86 \%\right)$ ) did not differ much from the questionnaires with fewer items (1-item questionnaire $R=$ 0.34 [95\% CI $0.30-0.39], \mathrm{I}^{2}: 68 \%$; 2 to 9-item questionnaires $R=0.35$ [95\% CI 0.29-0.41], $\mathrm{I}^{2}$ : 93\%) (Fig. 2a). Stratified analyses, including only studies examining questionnaires with a good-to-excellent quality, revealed similar results $(R$ questionnaires $=0.35$ [95\% CI 0.28 0.42], $\left.\mathrm{I}^{2}: 87 \%\right)$.

\section{Reliability}

Reliability for total sitting time and number of breaks in sitting time was determined in 44 studies. One study was rated with excellent quality; other studies were rated with good $(n=27)$, fair $(n=16)$, and poor $(n=8)$ quality. Most studies with a lower quality of the study were limited by a small sample size and calculation of correlation coefficients instead of ICCs. The time interval between the first and second assessment ranged between $0.5 \mathrm{~h}$ and 15 months, but most studies had an interval of $1-2$ weeks $(n=40$, Table 3$)$. The majority of the studies calculated the ICC to examine the test-retest reliability of $\mathrm{SB}$, but some studies used correlation coefficients $(N=6)$, BlandAltman plots with mean difference and limits of agreement $(N=2)$, and kappa values $(\mathrm{N}=2)$. The ICC of the test-retest reliability of the subjective measures of SB ranged between 0.44 and 0.91 (Table 3, Fig. 2b). The ICC estimates were comparable between the logs and diaries, $\geq 10$-items questionnaires, 2 to 9 -item questionnaires, and 1-item questionnaires.

\section{Discussion}

Time spent in SB has markedly increased over the last few decades and is expected to continue to increase even further [107]. Since SB is associated with many adverse health outcomes [4-6], exposure to excessive levels of SB represents an emerging health threat, particularly in the least physically active [108]. To improve quality and guide future studies in this rapidly expanding area of research, this systematic review assessed the validity and reliability of subjective measures of $\mathrm{SB}$, taking the methodological quality into account. We present the following observations. First, despite the presence of several measures to assess $\mathrm{SB}$, significant variability in measurement properties and quality of the studies is present. Second, criterion validity of the subjective measures ranged between poor to excellent ( $R$ range -0.01 to 0.90 ), in which the quality of most studies (i.e. level of evidence) was poor. Third, the validity of the logs/diaries was more favourable compared to the validity of questionnaires, with little improvement in validity of questionnaires when including multiple questions. Fourth, a moderate-to-good reliability was found for questionnaires and logs/diaries, with the quality of these studies being largely fair-to-good. Taken together, logs and diaries are recommended to validly and reliably assess SB when only self-report measures are available. However, considering limitations pertaining to logs and diaries (e.g. time constraint, resources), one may prefer using questionnaires in larger scaled observations.

\section{Validity of measures of SB}

This meta-analysis showed that the overall validity for instruments to assess SB characteristics was moderate to low. These observations raise the question whether these results relate to the poor validity of methods to assess SB per se or the poor quality of the studies that were included. Excluding studies with lower quality from our meta-analyses reinforced the poorto-moderate validity of the various methods, suggesting measures of SB possess poor validity. It is important to indicate that questionnaires examining physical activity show similarly poor level of validity [8]. This highlights the difficulty of examining subjective physical (in) activity behaviours with questionnaires, a finding that seems present across the whole physical activity spectrum: from SB to exercise. Due to the low validity and the large variation in quality, the results of different studies are difficult to compare or harmonise. More importantly, the large variety in validity and questionnaire characteristics (i.e. type and context of SBs) prevents the identification of one (or few) questionnaire(s) that can be recommended for all type of future research that aim to examine SB.

Factors explaining the poorer variation in validity of the questionnaires versus diaries/logs may relate to differences in qualitative attributes (e.g. recall period and questions/formats). For example, diaries/logs typically adopt a short recall period (e.g. every 15-30 min), whilst questionnaires are often filled in covering a longer recall period (i.e. day, week, and/or month). Consequently, diaries and logs are less reliant on long-term recall and can more accurately capture sporadic and intermittent behaviours. This fits with the higher validity of diaries/ logs versus questionnaires. Unfortunately, this approach of using diaries/logs comes with the cost of high participant burden (in time), which subsequently may limit the response and compliance rate and introduce reporting bias. Another potential limitation of logs/diaries is that repeatedly filling in SBs may influence participants' behaviour and cause (unwanted) adjustment of SB. These factors should be considered when deciding on the preferred way to assess SB in a future study. 
Previous work-related poor validity of questionnaires to systematic and random error, specifically reporting and recall bias which may lead to a low agreement with over- and underestimation (Table 2). For example, a potential underestimation of SB in single-item questionnaires was suggested [15, 104], whereas wider limits of agreement in questionnaires are present with multiple items [104]. Another factor contributing to validity of questionnaires may relate to the number of questions, and therefore detail of information, with more questions on SB potentially improving the criterion validity of the measurement tool. In contrast to this hypothesis, our analysis revealed no substantial differences between the criterion validity of the 1 -item, 2 -to-9-item and $\geq 10$-item questionnaires. One possible explanation is that participants find it difficult to recall SB, with multiple-item questionnaires making it even more complicated to replicate detailed and domain-specific patterns of SB [31]. Furthermore, some behaviours are easier to remember because these are more habitual and restricted to certain periods during the day, e.g. TV viewing, computer use or sitting at work [15, 31, 86]. Finally, multiple-item questionnaires may over-report SB because subjects may report sedentary activities twice when using sub-scales (e.g. driving while listing to music). Although more questions may cover multiple domains and provide more detailed information, the complexity of these questionnaires may contribute to the negligible improvement in criterion validity of multiple-item questionnaires for total sedentary time. Nonetheless, exploring multiple domains of sitting may still seem relevant. For example, some domains are more strongly associated with poor health outcomes [12-14], whilst detailed information about domains may provide insight for intervention development.

\section{Reliability of subjective measures of SB}

Despite the significant heterogeneity in validity of the various measures to assess $\mathrm{SB}$, the reliability of the questionnaires and diaries or logs were moderate-togood. Importantly, these conclusions are based on studies with a fair-to-good quality. A central question pertaining to the reliability of questionnaires is whether differences are present in reliability for weekdays versus weekend days or for workdays versus non-workdays, especially given the marked differences in (sedentary) behaviour that exist between these days [104]. Indeed, our study found that approximately $50 \%$ of included studies reported a $\geq 10 \%$ better reliability to assess SB during weekdays versus weekend days or during workdays versus non-workdays (Table 3). These observations support a previous review, which reported higher reliability for weekdays compared to weekend days [104]. Moreover, we found that reliability was better for specific behaviours, such as TV viewing, compared to a more general categories, such as 'other leisure time activities'. An explanation for this finding is that more specific and regularly performed behaviours have a higher reliability [15].

\section{Choosing an appropriate measurement tool}

Logs and diaries have a higher validity compared to the questionnaires, are less reliant on long-term recall and can more accurately capture sporadic and intermittent behaviours. Therefore, we recommend logs and dairies as self-reported measurement tools. However, important limitations such as time constrains, lack of resources and the potential to influence participants' behaviour, make them less useful for largescale observational studies and/or intervention studies. Within the spectrum of questionnaires, there is no obvious preference for a single questionnaire. In fact, the most appropriate tool seems to depend on the nature of the study, especially since this review showed large variety in both validity and questionnaire characteristics (i.e. type and context of SBs). Therefore, some studies will benefit from questionnaires focusing on specific domains of $\mathrm{SB}$, whilst others will benefit from a reliable estimate of total sedentary time or distribution of SB. Furthermore, when performing an intervention study, measures will benefit from the ability to measure changes across time. Since this ability was not examined within this review, we cannot make specific recommendations related to this type of studies. Nonetheless, these characteristics should be taken into account when planning such studies. Ultimately, and when feasible, a combination of objective and subjective assessments is preferred to provide valid and reliable insight into SB.

\section{Conclusions}

This review identified the widespread (and rapidly growing) use of a large range of self-reported measures of SB, which significantly differ in type, extensiveness, complexity and duration. Our results indicated that the criterion validity of subjective measures ranged between poor and excellent, whereas the quality of most studies was poor. The validity of the logs/diaries was significantly higher compared to the questionnaires, with little improvement in criterion validity of questionnaires when increasing items to assess SB. Therefore, when only self-report measures are feasible, logs and diaries are recommended to validly and reliably assess $\mathrm{SB}$, but due to time 
constraints and resources related to logs and diaries, 1 -item questionnaires may be preferred in large-scale studies when showing similar validity and reliability compared to longer questionnaires. Whenever feasible, the combination of objective and subjective assessments will provide the most valid and reliable method to assess SB.

\section{Supplementary information}

Supplementary information accompanies this paper at https://doi.org/10. 1186/s12966-020-00972-1.

Additional file :1 Table S1. Search strategy. Table S2. Assessing the quality of studies examining the criterion validity. Table S3. Assessing the quality of studies examining the reliability.

\section{Abbreviations}

ICC: Intra Correlation Coefficients; MET: Metabolic Equivalent of Task; R: Correlation Coefficient Estimate; SB: Sedentary Behaviour

\section{Acknowledgements}

Not applicable.

\section{Role of the funding body}

The content is solely the responsibility of the authors and does not necessarily represent the official views of previously mentioned the funding organizations described in the funding section.

\section{Authors' contributions}

All authors contributed to the study conception and design. EAB and YAW performed the literature searches, data extraction and quality assessments. The first draft of the manuscript was written by EAB and all authors commented on and revised previous versions of the manuscript. All authors read and approved the final manuscript.

\section{Funding}

T.M.H.E. is financially supported by a grant from the Dutch Heart Foundation (\#2017 T051). G.N.H. is supported by an Australian NHMRC Career Development Fellowship (\#1086029). D.W.D is supported by a NHMRC Senior Research Fellowship (NHMRC APP1078360) and supported in part by the Victorian Government's OIS Program.

\section{Availability of data and materials}

Not applicable.

\section{Ethics approval and consent to participate}

Not applicable.

\section{Consent for publication}

Not applicable.

\section{Competing interests}

The authors declare that they have no competing interests.

\section{Author details}

${ }^{1}$ Radboud Institute for Health Sciences, Department of Physiology, Radboud University Medical Center, P.O. Box 9101, 6500, HB, Nijmegen, The Netherlands. ${ }^{2}$ Research Institute for Sport and Exercise Sciences, Liverpoo John Moores University, Liverpool, UK. ${ }^{3}$ Baker Heart \& Diabetes Institute, Melbourne, Australia. ${ }^{4}$ Mary Mackillop Institute for Health Research, Australian Catholic University, Melbourne, Australia. ${ }^{5}$ The University of Queensland, School of Public Health, Brisbane, Australia.
Received: 5 December 2019 Accepted: 12 May 2020

Published online: 15 June 2020

\section{References}

1. Warburton DE, Katzmarzyk PT, Rhodes RE, Shephard RJ. Evidence-informed physical activity guidelines for Canadian adults. Can J Public Health. 2007; 98(Suppl 2):S16-68.

2. Bauman A LM, Schöppe S. The Health Benefits of Physical Activity in Developing Countries. Geneva: World Health Organization; 2005.

3. 2010 WHO. Global recommendations on physical activity for health. 2010 [07-08-2017]. Available from: http://www.who.int/dietphysicalactivity/ publications/9789241599979/en/.

4. Biswas A, Oh PI, Faulkner GE, Bajaj RR, Silver MA, Mitchell MS, et al. Sedentary time and its association with risk for disease incidence, mortality, and hospitalization in adults: a systematic review and meta-analysis. Ann Intern Med. 2015;162(2):123-32

5. van der Ploeg HP, Chey T, Korda RJ, Banks E, Bauman A. Sitting time and allcause mortality risk in 222497 Australian adults. Arch Intern Med. 2012; 172(6):494-500.

6. Eijsvogels TM, George KP, Thompson PD. Cardiovascular benefits and risks across the physical activity continuum. Curr Opin Cardiol. 2016;31(5):566-71.

7. Plasqui $G$, Bonomi AG, Westerterp KR. Daily physical activity assessment with accelerometers: new insights and validation studies. Obes Rev. 2013; 14(6):451-62.

8. van Poppel MN, Chinapaw MJ, Mokkink LB, van Mechelen W, Terwee CB. Physical activity questionnaires for adults: a systematic review of measurement properties. Sports Med. 2010;40(7):565-600.

9. Sedentary Behaviour Research N. Letter to the editor: standardized use of the terms "sedentary" and "sedentary behaviours". Appl Physiol Nutr Metab. 2012;37(3):540-2.

10. Tremblay MS, Aubert S, Barnes JD, Saunders TJ, Carson V, Latimer-Cheung $A E$, et al. Sedentary behavior Research network (SBRN) - terminology consensus project process and outcome. Int J Behav Nutr Phys Act. 2017; 14(1):75.

11. Byrom B, Stratton G, Mc Carthy M, Muehlhausen W. Objective measurement of sedentary behaviour using accelerometers. Int J Obes. 2016;40(11):180912.

12. Hu FB, Li TY, Colditz GA, Willett WC, Manson JE. Television watching and other sedentary behaviors in relation to risk of obesity and type 2 diabetes mellitus in women. JAMA. 2003;289(14):1785-91.

13. Kim Y, Wilkens LR, Park SY, Goodman MT, Monroe KR, Kolonel LN. Association between various sedentary behaviours and all-cause, cardiovascular disease and cancer mortality: the multiethnic cohort study. Int J Epidemiol. 2013;42(4):1040-56.

14. Ekelund U, Steene-Johannessen J, Brown WJ, Fagerland MW, Owen N, Powell KE, et al. Does physical activity attenuate, or even eliminate, the detrimental association of sitting time with mortality? A harmonised metaanalysis of data from more than 1 million men and women. Lancet. 2016; 388(10051):1302-10

15. Healy GN, Clark BK, Winkler EA, Gardiner PA, Brown WJ, Matthews CE. Measurement of adults' sedentary time in population-based studies. Am J Prev Med. 2011:41(2):216-27.

16. Dall PM, Coulter EH, Fitzsimons CF, Skelton DA, Chastin S, Seniors USPT. TAxonomy of self-reported Sedentary behaviour tools (TASST) framework for development, comparison and evaluation of self-report tools: content analysis and systematic review. BMJ Open. 2017;7(4):e013844.

17. Lopez-Rodriguez C, Laguna M, Gomez-Cabello A, Gusi N, Espino L, Villa G, et al. Validation of the self-report EXERNET questionnaire for measuring physical activity and sedentary behavior in elderly. Archives of Gerontology \& Geriatrics. 2017;69:156-61.

18. Laeremans M, Dons E, Avila-Palencia I, Carrasco-Turigas G, Orjuela JP, Anaya

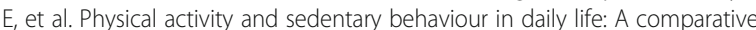
analysis of the Global Physical Activity Questionnaire (GPAQ) and the SenseWear armband. PLOS ONE [Electronic Resource]. 2017;12(5):e0177765.

19. Wanner M, Hartmann C, Pestoni G, Martin BW, Siegrist M, Martin-Diener E. Validation of the global physical activity questionnaire for selfadministration in a European context. BMJ Open Sport Exerc Med. 2017;3(1): e000206.

20. Cleland CL, Hunter RF, Kee F, Cupples ME, Sallis JF, Tully MA. Validity of the global physical activity questionnaire (GPAQ) in assessing levels and change 
in moderate-vigorous physical activity and sedentary behaviour. BMC Public Health. 2014;14:1255.

21. Chu AHY, Ng SHX, Koh D, Muller-Riemenschneider F. Domain-specific adult sedentary behaviour questionnaire (ASBQ) and the GPAQ single-item question: A reliability and validity study in an Asian population. International Journal of Environmental Research and Public Health. 2018;15 (4) (no pagination)(739)

22. Metcalf KM, Baquero BI, Coronado Garcia ML, Francis SL, Janz KF, Laroche $\mathrm{HH}$, et al. Calibration of the global physical activity questionnaire to Accelerometry measured physical activity and sedentary behavior. BMC Public Health. 2018;18(1):412

23. Rudolf K, Lammer F, Stassen G, Frobose I, Schaller A. Show cards of the global physical activity questionnaire (GPAQ) - do they impact validity? A crossover study. BMC Public Health. 2020;20(1):223.

24. Kastelic K, Sarabon N. Comparison of self-reported Sedentary time on weekdays with an objective measure (activPAL). Meas Phys Educ Exerc Sci. 2019;23(3):227-36.

25. Wanner M, Probst-Hensch N, Kriemler S, Meier F, Autenrieth C, Martin BW. Validation of the long international physical activity questionnaire: influence of age and language region. Prev Med Rep. 2016;3:250-6.

26. Craig $C L$, Marshall AL, Sjostrom M, Bauman AE, Booth ML, Ainsworth BE, et al. International physical activity questionnaire: 12-country reliability and validity. Med Sci Sports Exerc. 2003;35(8):1381-95.

27. Chastin SF, Culhane B, Dall PM. Comparison of self-reported measure of sitting time (IPAQ) with objective measurement (activPAL). Physiol Meas. 2014;35(11):2319-28

28. Chau JY, Van Der Ploeg HP, Dunn S, Kurko J, Bauman AE. Validity of the occupational sitting and physical activity questionnaire. Med Sci Sports Exerc. 2012;44(1):118-25.

29. Simpson K, Parker B, Capizzi J, Thompson P, Clarkson P, Freedson P, et al. Validity and reliability of question 8 of the Paffenbarger physical activity questionnaire among healthy adults. J Phys Act Health. 2015;12(1):116-23.

30. Larsson K, Kallings LV, Ekblom O, Blom V, Andersson E, Ekblom MM. Criterion validity and test-retest reliability of SED-GIH, a single item question for assessment of daily sitting time. BMC Public Health. 2019;19(1):17.

31. Chastin SFM, Dontje ML, Skelton DA, Cukic I, Shaw RJ, Gill JMR, et al. Systematic comparative validation of self-report measures of sedentary time against an objective measure of postural sitting (activPAL). International Journal of Behavioral Nutrition \& Physical Activity. 2018;15(1):21.

32. Aguilar-Farias N, Brown WJ, Olds TS, Geeske Peeters GM. Validity of selfreport methods for measuring sedentary behaviour in older adults. Journal of Science \& Medicine in Sport. 2015;18(6):662-6.

33. Clemes SA, David BM, Zhao Y, Han X, Brown W. Validity of two self-report measures of sitting time. J Phys Act Health. 2012;9(4):533-9.

34. Dontje ML, Dall PM, Skelton DA, Gill JMR, Chastin SFM. Reliability, minimal detectable change and responsiveness to change: Indicators to select the best method to measure sedentary behaviour in older adults in different study designs. PLOS ONE. 2018;13 (4) (no pagination)(e0195424)

35. Kozey-Keadle S, Libertine A, Staudenmayer J, Freedson P. The feasibility of reducing and measuring Sedentary time among overweight. Non-Exercising Office Workers Journal of Obesity. 2012;2012:282303.

36. Gennuso KP, Matthews CE, Colbert LH. Reliability and validity of 2 self-report measures to assess Sedentary behavior in older adults. J Phys Act Health. 2015;12(5):727-32

37. Gupta N, Christiansen CS, Hanisch C, Bay H, Burr H, Holtermann A. Is questionnaire-based sitting time inaccurate and can it be improved? A cross-sectional investigation using accelerometer-based sitting time. BM Open. 2017;7(1):e013251.

38. Chinapaw MJ, Slootmaker SM, Schuit AJ, van Zuidam M, van Mechelen W. Reliability and validity of the activity questionnaire for adults and adolescents (AQUAA). BMC Med Res Methodol. 2009;9:58.

39. Rees-Punia E, Matthews CE, Evans EM, Keadle SK, Anderson RL, Gay JL, et al. Demographic-specific validity of the Cancer prevention Study-3 Sedentary time survey. Med Sci Sports Exerc. 2019;51(1):41-8.

40. Hekler EB, Buman MP, Haskell WL, Conway TL, Cain KL, Sallis JF, et al. Reliability and validity of CHAMPS self-reported sedentary-to-vigorous intensity physical activity in older adults. J Phys Act Health. 2012;9(2): 225-36.

41. Matton L, Wijndaele K, Duvigneaud N, Duquet W, Philippaerts R, Thomis M, et al. Reliability and validity of the Flemish physical activity computerized questionnaire in adults. Research Quarterly for Exercise \& Sport. 2007;78(4) 293-306.

42. Scheers T, Philippaerts R, Lefevre J. Assessment of physical activity and inactivity in multiple domains of daily life: a comparison between a computerized questionnaire and the SenseWear armband complemented with an electronic diary. International Journal of Behavioral Nutrition \& Physical Activity. 2012;9:71.

43. Prince SA, Reid RD, Bernick J, Clarke AE, Reed JL. Single versus multi-item self-assessment of sedentary behaviour: a comparison with objectively measured sedentary time in nurses. Journal of Science \& Medicine in Sport. 2018;08:08.

44. Rosenberg DE, Bull FC, Marshall AL, Sallis JF, Bauman AE. Assessment of sedentary behavior with the international physical activity questionnaire. J Phys Act Health. 2008;5(Suppl 1):S30-44.

45. Kozey Keadle S, Lyden K, Hickey A, Ray EL, Fowke JH, Freedson PS, et al. Validation of a previous day recall for measuring the location and purpose of active and sedentary behaviors compared to direct observation. International Journal of Behavioral Nutrition \& Physical Activity. 2014;11:12.

46. Ferguson S, Ellis G, Hunter RF. Validity of the international physical activity questionnaire (IPAQ) for assessing moderate-to-vigorous physical activity and sedentary behaviour of older adults in the United Kingdom. BMC Med Res Methodol. 2018;18(1):176.

47. Ryan DJ, Wullems JA, Stebbings GK, Morse Cl, Stewart CE, OnambelePearson GL. Reliability and validity of the international physical activity questionnaire compared to calibrated accelerometer cut-off points in the quantification of sedentary behaviour and physical activity in older adults. PLoS ONE. 2018;13 (4) (no pagination)(e0195712).

48. Reis JP, Durbose KD, Ainsworth BE, Macera CA, Yore MM. Reliability and validity of the occupational physical activity questionnaire. Med Sci Sports Exerc. 2005;37(12):2075-83.

49. Pedersen SJ, Kitic CM, Bird ML, Mainsbridge CP, Cooley PD. Is self-reporting workplace activity worthwhile? Validity and reliability of occupational sitting and physical activity questionnaire in desk-based workers. BMC Public Health. 2016;16(1):836.

50. van Nassau F, Chau JY, Lakerveld J, Bauman AE, van der Ploeg HP. Validity and responsiveness of four measures of occupational sitting and standing. International Journal of Behavioral Nutrition \& Physical Activity. 2015;12:144.

51. Jancey J, Tye M, McGann S, Blackford K, Lee AH. Application of the occupational sitting and physical activity questionnaire (OSPAQ) to office based workers. BMC Public Health. 2014;14:762.

52. Pedersen ESL, Mortensen LH, Brage S, Bjerregaard AL, Aadahl M. Criterion validity of the physical activity scale (PAS2) in Danish adults. Scandinavian Journal of Public Health. 2017;1403494817738470.

53. Scholes S, Coombs N, Pedisic Z, Mindell JS, Bauman A, Rowlands AV, et al Age- and sex-specific criterion validity of the health survey for England physical activity and Sedentary behavior assessment questionnaire as compared with accelerometry. Am J Epidemiol. 2014;179(12):1493-502.

54. Fowles JR, O'Brien MW, Wojcik WR, d'Entremont L, Shields CA. A pilot study: validity and reliability of the CSEP-PATH PASB-Q and a new leisure time physical activity questionnaire to assess physical activity and sedentary behaviours. Applied physiology, nutrition, \& metabolism = Physiologie Appliquee. Nutrition et Metabolisme. 2017;42(6):677-80.

55. Clark BK, Pavey TG, Lim RF, Gomersall SR, Brown WJ. Past-day recall of sedentary time: validity of a self-reported measure of sedentary time in a university population. Journal of Science \& Medicine in Sport. 2016;19(3): 237-41.

56. Yi SS, Bartley KF, Firestone MJ, Lee KK, Eisenhower DL. Self-reported sitting time in New York City adults, the physical activity and transit survey, 20102011. Prev Chronic Dis. 2015;12:E85.

57. Golubic R, May AM, Benjaminsen Borch K, Overvad K, Charles MA, Diaz MJ, et al. Validity of electronically administered Recent Physical Activity Questionnaire (RPAQ) in ten European countries. [Erratum appears in PLoS One. 2014;9(11):e114103]. PLoS ONE [Electronic Resource]. 2014;9(3):e92829.

58. Besson H, Brage S, Jakes RW, Ekelund U, Wareham NJ. Estimating physical activity energy expenditure, sedentary time, and physical activity intensity by self-report in adults. Am J Clin Nutr. 2010;91(1):106-14.

59. Molina L, Sarmiento M, Penafiel J, Donaire D, Garcia-Aymerich J, Gomez M, et al. Validation of the Regicor Short Physical Activity Questionnaire for the Adult Population. PLoS ONE [Electronic Resource]. 2017;12(1):e0168148.

60. Buchowski MS, Matthews CE, Cohen SS, Signorello LB, Fowke JH, Hargreaves $M K$, et al. Evaluation of a questionnaire to assess sedentary and active 
behaviors in the southern community cohort study. J Phys Act Health. 2012; 9(6):765-75.

61. Pedisic Z, Bennie JA, Timperio AF, Crawford DA, Dunstan DW, Bauman AE, et al. Workplace sitting breaks questionnaire (SITBRQ): an assessment of concurrent validity and test-retest reliability. BMC Public Health. 2014;14: 1249.

62. Gardiner PA, Clark BK, Healy GN, Eakin EG, Winkler EA, Owen N. Measuring older adults' sedentary time: reliability, validity, and responsiveness. Med Sci Sports Exerc. 2011;43(11):2127-33.

63. Mensah K, Maire A, Oppert JM, Dugas J, Charreire H, Weber C, et al. Assessment of sedentary behaviors and transport-related activities by questionnaire: a validation study. BMC Public Health. 2016;16:753.

64. Gennuso KP, Thraen-Borowski KM, Gangnon RE, Colbert LH. Patterns of sedentary behavior and physical function in older adults. Aging-Clinical \& Experimental Research. 2016;28(5):943-50.

65. Bonn SE, Bergman P, Trolle Lagerros Y, Sjolander A, Balter K. A validation study of the web-based physical activity questionnaire active- $\mathrm{Q}$ against the GENEA accelerometer. JMIR Research Protocols. 2015;4(3):e86.

66. Matsuo T, Sasai H, So R, Ohkawara K. Percentage-method improves properties of Workers' sitting- and walking-time questionnaire. Journal of Epidemiology. 2016;26(8):405-12.

67. Clark BK, Thorp AA, Winkler EA, Gardiner PA, Healy GN, Owen N, et al. Validity of self-reported measures of workplace sitting time and breaks in sitting time. Med Sci Sports Exerc. 2011:43(10):1907-12.

68. Jefferis BJ, Sartini C, Ash S, Lennon LT, Wannamethee SG, Whincup PH. Validity of questionnaire-based assessment of sedentary behaviour and physical activity in a population-based cohort of older men; comparisons with objectively measured physical activity data. International Journal of Behavioral Nutrition \& Physical Activity. 2016;13:14.

69. Lagersted-Olsen J, Korshoj M, Skotte J, Carneiro IG, Sogaard K, Holtermann A. Comparison of objectively measured and self-reported time spent sitting. Int J Sports Med. 2014;35(6):534-40.

70. Mielke Gl, Crochemore M da Silva I, Gomersall SR, Owen N, Hallal PC. Reliability of a multi-domain sedentary behaviour questionnaire and comparability to an overall sitting time estimate. J Sports Sci 2020;38(3): 351-356.

71. Sudholz B, Ridgers ND, Mussap A, Bennie J, Timperio A, Salmon J. Reliability and validity of self-reported sitting and breaks from sitting in the workplace. Journal of Science \& Medicine in Sport. 2017;07:07.

72. Cartmel B, Moon TE. Comparison of two physical activity questionnaires, with a diary, for assessing physical activity in an elderly population. J Clin Epidemiol. 1992;45(8):877-83.

73. Anjana RM, Sudha V, Lakshmipriya N, Subhashini S, Pradeepa R, Geetha L, et al. Reliability and validity of a new physical activity questionnaire for India. International Journal of Behavioral Nutrition \& Physical Activity. 2015 12:40.

74. Whitfield GP, Gabriel KK, Kohl HW 3rd. Assessing sitting across contexts: development of the multicontext sitting time questionnaire. Research Quarterly for Exercise \& Sport. 2013;84(3):323-8.

75. Verhoog S, Gubelmann C, Guessous I, Bano A, Franco OH, Marques-Vidal P. Comparison of the physical activity frequency questionnaire (PAFQ) with accelerometry in a middle-aged and elderly population: the CoLaus study. Maturitas. 2019;129:68-75.

76. Moulin MS, Lee CJ, Tucker P, Prapavessis H, Irwin JD. Weekly recall of sedentary time: validity of 2 weekly self-reported measures in undergraduate students. Translational Sports Medicine. 2020;3(2):127-33.

77. Rosenberg DE, Norman GJ, Wagner N, Patrick K, Calfas KJ, Sallis JF. Reliability and validity of the Sedentary behavior questionnaire (SBQ) for adults. J Phys Act Health. 2010;7(6):697-705.

78. Lynch BM, Friedenreich CM, Khandwala F, Liu A, Nicholas J, Csizmadi I. Development and testing of a past year measure of sedentary behavior: the SIT-Q. BMC Public Health. 2014;14:899.

79. Busschaert C, De Bourdeaudhuij I, Van Holle V, Chastin SF, Cardon G, De Cocker K. Reliability and validity of three questionnaires measuring contextspecific sedentary behaviour and associated correlates in adolescents, adults and older adults. International Journal of Behavioral Nutrition \& Physical Activity. 2015;12:117.

80. Wijndaele K, De Bourdeaudhuij I, Godino JG, Lynch BM, Griffin SJ, Westgate $\mathrm{K}$, et al. Reliability and validity of a domain-specific last 7-d Sedentary time questionnaire. Med Sci Sports Exerc. 2014;46(6):1248-60.
81. Csizmadi I, Neilson HK, Kopciuk KA, Khandwala F, Liu A, Friedenreich CM, et al. The Sedentary time and activity reporting questionnaire (STAR-Q): reliability and validity against doubly labeled water and 7-day activity diaries. Am J Epidemiol. 2014;180(4):424-35.

82. Chau JY, van der Ploeg HP, Dunn S, Kurko J, Bauman AE. A tool for measuring workers' sitting time by domain: the workforce sitting questionnaire. Br J Sports Med. 2011;45(15):1216-22.

83. Toledo MLL, Mullane SL, Larouche ML, Rydell SA, Mitchell NR, Pereira MA, et al. Stand and Move at Work sedentary behavior questionnaire: validity and sensitivity to change. Annals of Epidemiology. 2019;31:62-8.e1.

84. Clark BK, Lynch BM, Winkler EA, Gardiner PA, Healy GN, Dunstan DW, et al. Validity of a multi-context sitting questionnaire across demographically diverse population groups: AusDiab3. International Journal of Behavioral Nutrition \& Physical Activity. 2015;12:148.

85. Ishii K, Shibata A, Kurita S, Yano S, Inoue S, Sugiyama T, et al. Validity and reliability of Japanese-language self-reported measures for assessing adults domain-specific Sedentary time. Journal of epidemiology. 2018;28(3):149-55.

86. Marshall AL, Miller YD, Burton NW, Brown WJ. Measuring total and domainspecific sitting: a study of reliability and validity. Med Sci Sports Exerc. 2010; 42(6):1094-102.

87. Van Cauwenberg J, Van Holle V, De Bourdeaudhuij I, Owen N, Deforche B. Older adults' reporting of specific sedentary behaviors: validity and reliability. BMC Public Health. 2014;14:734.

88. Visser M, Koster A. Development of a questionnaire to assess sedentary time in older persons--a comparative study using accelerometry. BMC Geriatr. 2013;13:80.

89. Barwais FA, Cuddihy TF, Washington T, Tomson LM, Brymer E. Development and validation of a new self-report instrument for measuring sedentary behaviors and light-intensity physical activity in adults. J Phys Act Health. 2014;11(6):1097-104.

90. Hart TL, Ainsworth BE, Tudor-Locke C. Objective and subjective measures of sedentary behavior and physical activity. Med Sci Sports Exerc. 2011;43(3): 449-56.

91. Toledo MJ, Hekler E, Hollingshead K, Epstein D, Buman M. Validation of a smartphone app for the assessment of Sedentary and active behaviors. JMIR MHealth and UHealth. 2017:5(8):e119.

92. Kohler S, Behrens G, Olden M, Baumeister SE, Horsch A, Fischer B, et al. Design and evaluation of a computer-based 24-hour physical activity recall (cpar24) instrument. J Med Internet Res. 2017;19(5):e186.

93. Knell G, Gabriel KP, Businelle MS, Shuval K, Wetter DW, Kendzor DE. Ecological momentary assessment of physical activity: validation study. J Med Internet Res. 2017;19(7):e253.

94. Gomersall SR, Pavey TG, Clark BK, Jasman A, Brown WJ. Validity of a selfreport recall tool for estimating Sedentary behavior in adults. J Phys Act Health. 2015;12(11):1485-91.

95. Kim $Y$, Welk GJ. The accuracy of the 24 -h activity recall method for assessing sedentary behaviour: the physical activity measurement survey (PAMS) project. J Sports Sci. 2017;35(3):255-61.

96. van der Ploeg HP, Merom D, Chau JY, Bittman M, Trost SG, Bauman AE. Advances in population surveillance for physical activity and sedentary behavior: reliability and validity of time use surveys. Am J Epidemiol. 2010; 172(10):1199-206.

97. Matthews CE, Keadle SK, Sampson J, Lyden K, Bowles HR, Moore SC, et al. Validation of a previous-day recall measure of active and sedentary behaviors. Med Sci Sports Exerc. 2013;45(8):1629-38.

98. Liberati A, Altman DG, Tetzlaff J, Mulrow C, Gotzsche PC, loannidis JP, et al. The PRISMA statement for reporting systematic reviews and meta-analyses of studies that evaluate healthcare interventions: explanation and elaboration. BMJ. 2009:339:b2700.

99. Mokkink LB, Terwee CB, Knol DL, Stratford PW, Alonso J, Patrick DL, et al. The COSMIN checklist for evaluating the methodological quality of studies on measurement properties: a clarification of its content. BMC Med Res Methodol. 2010;10:22.

100. Mokkink LB, Terwee CB, Patrick DL, Alonso J, Stratford PW, Knol DL, et al. The COSMIN checklist for assessing the methodological quality of studies on measurement properties of health status measurement instruments: an international Delphi study. Qual Life Res. 2010;19(4):539-49.

101. Terwee CB, Mokkink LB, Knol DL, Ostelo RW, Bouter LM, de Vet HC. Rating the methodological quality in systematic reviews of studies on measurement properties: a scoring system for the COSMIN checklist. Qual Life Res. 2012;21(4):651-7. 
102. Gao Y, Cronin NJ, Nevala N. Finni T. Journal of Sport and Health Science: Validity of long-term and short-term recall of occupational sitting time in Finnish and Chinese office workers; 2017.

103. HCW de Vet CT, LB Mokkink, DL Knol. Measurement in Medicine : A Practical Guide. Cambridge: Cambridge University Press; 2011.

104. Atkin AJ, Gorely T, Clemes SA, Yates T, Edwardson C, Brage S, et al. Methods of measurement in epidemiology: sedentary Behaviour. Int J Epidemiol. 2012;41(5):1460-71.

105. Koo TK, Li MY. A guideline of selecting and reporting Intraclass correlation coefficients for reliability Research. J Chiropr Med. 2016;15(2):155-63.

106. Haddock S. Analyzing effect sizes: Fixed-effects models. The handbook of research synthesis and meta analysis: New York: Russell Sage Foundation.; 2009. p. pp. 257-78.

107. Yang L, Cao C, Kantor ED, Nguyen LH, Zheng X, Park Y, et al. Trends in Sedentary behavior among the US population, 2001-2016. JAMA. 2019; 321(16):1587-97.

108. Ng SW, Popkin BM. Time use and physical activity: a shift away from movement across the globe. Obes Rev. 2012;13(8):659-80.

\section{Publisher's Note}

Springer Nature remains neutral with regard to jurisdictional claims in published maps and institutional affiliations.

Ready to submit your research? Choose BMC and benefit from:

- fast, convenient online submission

- thorough peer review by experienced researchers in your field

- rapid publication on acceptance

- support for research data, including large and complex data types

- gold Open Access which fosters wider collaboration and increased citations

- maximum visibility for your research: over $100 \mathrm{M}$ website views per year

At BMC, research is always in progress.

Learn more biomedcentral.com/submissions 